\title{
LES/PDF modeling of swirl-stabilized non-premixed methane/air flames with local extinction and re-ignition
}

Short title: LES/PDF modeling of swirl-stabilized non-premixed methane/air flames with local extinction and re-ignition

The corrections made in this section will be reviewed and approved by a journal production editor.

\section{S. Yu ${ }^{\mathrm{a}}$, X. Liu ${ }^{\mathrm{a}, \mathrm{c}}$, X.S. Bai ${ }^{\mathrm{a}, *}$ Xue-Song.Bai@energy.lth.se, A.M. Elbaz ${ }^{\mathrm{b}, \mathrm{d}}$, W.L. Roberts ${ }^{\mathrm{b}}$}

${ }^{\text {a} D i v i s i o n ~ o f ~ F l u i d ~ M e c h a n i c s, ~ D e p a r t m e n t ~ o f ~ E n e r g y ~ S c i e n c e s, ~ L u n d ~ U n i v e r s i t y, ~ L u n d ~ 22100, ~ S w e d e n ~}$

${ }^{\mathbf{b}}$ Clean Combustion Research Center, King Abdullah University of Science and Technology, Saudi Arabia ${ }^{\mathbf{c}}$ College of Power and Energy Engineering, Harbin Engineering University, Harbin, Heilongjiang 150001, China

${ }^{\mathbf{d}}$ Faculty of Engineering, Helwan University, Cairo, Egypt

*Corresponding author.

\begin{abstract}
Turbulent non-premixed flames with local extinction and re-ignition exhibit multiple combustion modes including ignition waves, diffusion flames, partially premixed flames, and ignition-assisted partially premixed flames. The mechanisms of local extinction and re-ignition are not well understood and numerical modeling of multi-mode combustion is a challenging task. In this work, a specially designed swirl-burner was used to study local extinction and re-ignition of non-premixed turbulent methane/air flames. High speed Particle Image Velocimetry (PIV) and laser induced fluorescence of $\mathrm{OH}$ radicals (OH-PLIF) measurements along with Large Eddy Simulation (LES) were carried out to investigate the mechanisms of extinction and re-ignition processes in the burner. LES is based on a transported probability density function model within the framework of Eulerian Stochastic Fields (PDF-ESF). It is found that local extinction occurs when the scalar dissipation rate around the stoichiometric mixture fraction is high. The characteristic time scale for local extinction and reignition in the present flames is an order of magnitude longer than the characteristic time scale of diffusion/extinction of laminar flamelets. There are two mechanisms for flame hole re-ignition in the present flames. First, under low degree of local extinction conditions (i.e., for small flame holes surrounded by flames) the flame hole re-ignition is due to the mechanism of turbulent flame folding. Second, under high degree of extinction conditions (i.e., with large regions of extinction and lifted flames), re-ignition of the locally extinguished flame is due to the mechanism of ignition assisted partially premixed flame propagation. The results show that the PDF-ESF model is capable of simulating the quenching and re-ignition process found in the experiments.
\end{abstract}


Keywords: LES; PDF-ESF; Non-premixed swirl flames; Local extinction; Re-ignition

\section{Introduction}

Local flame extinction is a phenomenon frequently observed in turbulent non-premixed flames. The location of the extinction may vary depending on the flow dynamics, transport processes, and chemical reactions. Several mechanisms for the local flame extinction have been discussed in the literature. It is well understood that the flame extinguishes in regions of high scalar dissipation rate [1-5]. Some authors have reported local flame extinction due to high-level fluctuations of scalar dissipation rate [6-8], e.g., in the near field of jet flames. There are also results showing local flame extinction due to the unsteady radial movement of vortices originating from the fuel flow stream of lifted methane/air jet flames [9-11]. For more complex flame configurations, e.g., swirling non-premixed flames, the scenario for local flame extinction can be more complex $[5,12]$. In the Sydney swirl flames, the local extinction did not seem to correlate with the instability of the fuel jet [5]; instead, local flame extinction was shown to originate from outer radial locations closer to the coflow air than to the fuel jet [12].

The local fuel/air mixture in the extinction region may re-ignite downstream forming a flame hole. Re-ignition of the extinction region may be due to the mechanism of turbulent flame folding, in which the turbulent transport plays a dominant role. In this mechanism, re-ignition occurs through heat and mass transfer, by bringing hot gas into contact (and mixing) with unburnt reactants [13-15], and by transporting radicals from neighbouring burning flamelets [16,17]. Edge flame propagation is another mechanism for re-ignition, in which the edge of the downstream flame propagates inwards along the stoichiometric surface into the extinguished region $[13,18,19]$. This mechanism indicates a flame controlled process after the extinction of a diffusion flame disk [20-22] and the flame leading edge is partially premixed [23,24]. Steinberg et al. [19], Juddoo and Masri [25], Elbaz and Roberts [26] found that the edge flame propagation mechanism dominates the re-ignition process in several flame types. Upstream of the edge flame front in the non-premixed lifted flame, a locally extinguished state provides a mixing condition for the reactants, leading to a nearly premixed flame [27-31]. A review on the studies of edge flame has been given by Buckmaster [32].

Though there is still a lack of general consensus on the mechanisms of local extinction and re-ignition in turbulent non-premixed flames, it is clear that multiple combustion modes can exist when local extinction and reignition occur, e.g., diffusion flame, edge flame, premixed flame, and ignition front propagation. This poses a challenge to the application of specifically designed turbulent combustion models to simulate such flames. For example, Kempf et al. [33] performed numerical simulations of the Sydney swirl flames using a stationary flamelet model; they reported a well-predicted recirculation flow structure but a less satisfactory prediction of the extinction events. Several authors have confirmed that models based on a single scalar alone could not predict the local extinction and re-ignition process, e.g., mixture fraction based flamelet models [34] or conventional conditional moment closure (CMC) model based on singly conditioning on mixture fraction $[35,36]$. This is because that conditioning of temperature (and species mass fractions) on mixture fraction and scalar dissipation rate does not collapse the data from flames with local extinction and re-ignition onto the same curve at low scalar dissipation rates as expected from the flamelet model [37]. It is recognized that to model local extinction and reignition at least two variables are needed: one variable describing the mixing of fuel and oxidizer and a second variable allowing for the distinction between burning and non-burning regions [38]. Kronenburg et al. presented an extended CMC model by doubly conditioning on two variables, a sensible enthalpy that represents the reaction progress variable and the mixture fraction that represents the mixing process [38,39]. The doubly conditioned moment closure method showed promising results for predicting local extinction, the onset of re- 
ignition, and the occurrence of global extinction when comparing with results obtained from direct numerical simulations (DNS). Recently, it has been shown that by taking into account the convective and sub-grid scale conditional flux terms in the CMC equation (referred to as 3D-CMC), the model can capture the local extinction and re-ignition process in Sandia flame F [16] and a swirl-stabilized non-premixed flame [40]. Along the line of flamelet/progress variable (FPV) modeling, Ihme and Pitsch $[34,41]$ reported that the modeling of the presumed probability density function (PDF) for the reactive scalar and the consideration of unsteady effects were of particular importance during local flame extinction and subsequent re-ignition. The models for the presumed PDFs for conserved and reactive scalars were re-examined and a statistically most likely distribution (SMLD) was employed and tested in a priori studies using DNS data and experimental results from the Sandia flame series. SMLD is able to enforce an arbitrary amount of moment information and the consideration of time scale information. For Sandia Flames D and E, the extended FPV model with SMLD showed good predictions of mixture-fraction-conditioned results, although with the over-prediction of the consumption of fuel and oxidizer on the fuel-rich side, resulting in an over-prediction of minor species.

It is expected that multi-mode combustion process requires a model-free simulation approach such as DNS [42] or simulations with turbulent combustion models that are combustion mode and regime independent. One such model is the transported probability density (PDF) model. Masri and Pope [43] applied the PDF method to predict turbulent non-premixed jet flames. However, due to the use of one-step chemical kinetic mechanism, the local extinction event was not properly captured. Tang et al. [44] incorporated a multi-step chemical kinetic mechanism into the PDF model and they demonstrated that the model was capable of replicating local extinction and re-ignition processes fairly well. For swirling non-premixed flames, e.g., the Sydney non-premixed swirling flame series, the earlier work of Masri et al. [45] showed promising predictions of the flow field using the transported PDF model, and James et al. [46] showed good prediction of temperature and flow fields using the transported PDF model. More recently, Jones and co-workers have reported successful applications of the transported PDF method coupled with LES for the simulation of various flames, for example, local extinction in Sandia flame series [47], Sydney piloted flames [48], auto-ignition in a hydrogen jet flame stabilized in a co-flow of vitiated air [49], premixed swirling flames [50], and partially-premixed swirling flames [51]. Brauner et al. [52] validated the PDF model on Cambridge stratified swirling flames by reproducing the velocities and major species profiles with a good accuracy. In the LES framework, the PDF modelling uncertainties are believed to be alleviated due to the well resolved time fluctuations and small sub-grid fluctuations [53]. Thus, with the growing computational capability, PDF coupled with LES is expected to be reliable in predicting the non-premixed swirling flames.

Turbulent non-premixed swirling flames are widely used in engineering combustion devices such as aeroengines. Due to the complexity of interactions between flow fields and combustion in non-premixed swirling flames, the mechanisms of flame extinction and re-ignition are not well understood. Very recently, Elbaz et al. [54-56] reported a series of experimental studies of local extinction and re-ignition in turbulent non-premixed flames stabilized in a co-centric conical swirl burner using PIV and OH PLIF imaging. The experiments clearly demonstrated the transition from burner-attached non-premixed swirling flames to flames with local extinction and re-ignition, and finally to flame liftoff and blowout. It was found that the onset of local extinction in the burner was sensitive to the burner exit geometry. For a given swirl number, the burner with a diverging quarl was more resilient to local extinction than the burner without the quarl. The stability regime of the burner with the diverging quarl was much wider than that without the quarl.

In the present work, LES with transported PDF model in the framework of ESF is carried out to study the local extinction and re-ignition process in turbulent swirling non-premixed flames of Elbaz et al. [56]. The objectives 
of this study are (i) to investigate the mechanisms of local extinction and re-ignition in this class of turbulent nonpremixed swirling flames, and (ii) to evaluate the performance of LES-PDF model for prediction of turbulent non-premixed swirl flames with local extinction and re-ignition. The experimental flame of Elbaz et al. [56] is selected due to the available experimental data that includes a wide range of experimental conditions covering burner-attached diffusion flames, and flames with local extinction and re-ignition.

\section{Numerical methods}

In LES of turbulent reactive flows, the transport equations consist of the spatially filtered Navier-Stokes equations, and transport equations for reactive scalars, etc. $[47,48]$. As an example, transport equation for the filtered species mass fraction, $\widetilde{Y}_{\alpha}$, is expressed as follows:

$$
\frac{\partial \bar{\rho} \widetilde{Y}_{\alpha}}{\partial t}+\frac{\partial \bar{\rho} \tilde{u}_{i} \widetilde{Y}_{\alpha}}{\partial x_{i}}=\frac{\partial}{\partial x_{i}}\left(\bar{\rho}_{i} \widetilde{Y}_{\alpha}-\overline{\rho u_{i} Y_{\alpha}}\right)-\frac{\partial \bar{J}_{\alpha, i}}{\partial x_{i}}+\bar{\rho} \widetilde{\omega}_{\alpha}
$$

where $\overline{(\ldots)}$ denotes spatial filtering and $\widetilde{(\ldots)}$ denotes density weighted spatial filtering, viz., $\bar{\phi}=\int_{\Omega} \phi(\mathbf{y}, t) G(\mathbf{x}-\mathbf{y} ; \Delta(\mathbf{x})) d \mathbf{y}$, and $\widetilde{\phi}=\overline{\rho \phi} / \bar{\rho}$, with $G(\mathbf{x}-\mathbf{y} ; \Delta(\mathbf{x}))$ and $\Delta(\mathbf{x})$ being the filter function and filter width, respectively. $\bar{J}_{\alpha, i}$ is the filtered molecular transport flux for species $\alpha$ along $x_{i}$ direction, and $\tilde{\omega}_{\alpha}$ is the filtered chemical reaction rate of species $\alpha$. The large eddy motion is described by the filtered quantities $\left(\rho, \widetilde{u}_{i}, \widetilde{Y}_{\alpha}\right)$ obtained from the above equation. The sub-grid scale (SGS) effect is taken into account in the term $\widetilde{\rho}_{i} \widetilde{Y}_{\alpha}-\overline{\rho u_{i} Y_{\alpha}}$. Following the work of Jones et al. [50], the sub-grid scalar flux and the sub-grid stress (for the momentum equations) are modeled using the Smagorinsky model [57], viz., for the scalar fluxes,

$$
\widehat{\rho}_{i} \widetilde{Y}_{\alpha}-\overline{\rho u_{i} Y_{\alpha}}=\frac{\mu_{s g s}}{\sigma_{s g s}} \frac{\partial \widetilde{Y}_{\alpha}}{\partial x_{i}}
$$

where $\mu_{s g s}$ is modeled as $\mu_{s g s}=\left(C_{s} \Delta\right)^{2} \bar{\rho}\left|\widetilde{S}_{i j}\right|$ with $\left|\widetilde{S}_{i j}\right|=\sqrt{2 \widetilde{S}_{i j} \widetilde{S}_{i j}}$ denoting the mean strain rate tensor. The Smagorinsky constant $C_{s}$ is set a value of $0.17 ; \sigma_{s g s}$ is the turbulent Prandtl/Schmidt number, assigned a value of 0.7, equal for all species [48,58,59]. A single-time one-point joint PDF $P_{s g s}(\psi ; x, t)$ describing the random motion in the sub-grid scale is expressed as:

$$
P_{s g s}(\underline{\psi} ; \mathbf{x}, t)=\int_{\Omega} \mathscr{F}(\underline{\psi} ; \mathbf{y}, t) G(\mathbf{x}-\mathbf{y} ; \Delta(\mathbf{x})) d \mathbf{y}
$$

in which $\mathscr{F}(\underline{\psi} ; \mathbf{y}, t)=\prod_{k=1}^{N_{s}} \delta\left(\psi_{k}-\phi_{k}\right)(\mathbf{y}, t)$ is the fine-grained PDF, and $N_{s}$ is the number of scalars calculated in the governing equation. $\psi_{-}$represents the sample space of the random scalar quantities $\phi_{-}$with $\delta$ denoting the Dirac delta function. $P_{s g s}$ is the probability of observing the random variables $\underline{\phi}=\underline{\psi}$. The evolution of the density-weighted PDF, $\widetilde{P}_{s g s}=(1 / \bar{\rho}) \int_{\Omega} \rho(\mathbf{y}) \mathscr{F}(\underline{\psi} ; \mathbf{y}, t) G(\mathbf{x}-\mathbf{y} ; \Delta(\mathbf{x})) d \mathbf{y}$, can be derived from conservation equations, see e.g. [49,60]: 
where the quantity in the angle bracket $\left\langle Q \mid \psi_{-}\right\rangle$represents the mean conditioned on the scalars having the

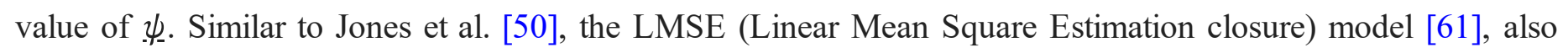
known as the IEM (interaction by exchanging with the mean) model [62], is adopted for the micro-mixing term. This model has shown promising results in various applications $[58,63]$. The above joint PDF equation can be written as:

$$
\begin{aligned}
& \frac{\partial}{\partial t}\left(\bar{\rho} \widetilde{P}_{s g s}\right)+\frac{\partial}{\partial x_{i}}\left(\widetilde{\rho u}_{i} \widetilde{P}_{s g s}\right)+\sum_{\alpha=1}^{N_{s}} \frac{\partial}{\partial \psi_{\alpha}}\left[\bar{\rho} \dot{\omega}_{\alpha} \widetilde{P}_{s g s}\right] \\
= & \frac{\partial}{\partial x_{i}}\left[\Gamma_{t} \frac{\partial \widetilde{P}_{s g s}}{\partial x_{i}}\right]+\frac{\bar{\rho} C_{\phi}}{2 \tau_{s g s}} \sum_{\alpha=1}^{N_{s}} \frac{\partial}{\partial \psi_{\alpha}}\left[\left(\psi_{\alpha}-\widetilde{\phi}_{\alpha}(\mathbf{x}, t)\right) \widetilde{P}_{s g s}\right]
\end{aligned}
$$

Eq. (5) is solved using the Eulerian Stochastic Fields (ESF) method proposed by Valino [64]. In the ESF method, the joint sub-grid PDF is determined from $N$ stochastic fields $\xi_{\alpha}^{n}(\mathbf{x}, t)$ for each of the scalars $\psi_{\alpha}$, $\alpha=1, \ldots, N_{s}, n=1, \ldots, N$ :

$$
\widetilde{P}_{s g s}(\underline{\psi} ; \mathbf{x}, t)=\frac{1}{N} \sum_{n=1}^{N} \prod_{\alpha=1}^{N_{s}} \delta\left(\psi_{\alpha}-\xi_{\alpha}^{n}(\mathbf{x}, t)\right)
$$

The governing equation of the $n^{\text {th }}$ stochastic field $\left(\xi_{\alpha}^{n}\right)$ can be written as:

$$
\begin{gathered}
\bar{\rho} d \xi_{\alpha}^{n}=-\bar{\rho} \widetilde{u}_{i} \frac{\partial \xi_{\alpha}^{n}}{\partial x_{i}} d t+\frac{\partial}{\partial x_{i}}\left(\Gamma_{t} \frac{\partial \xi_{\alpha}^{n}}{\partial x_{i}}\right) d t+\bar{\rho} \sqrt{2 \frac{\Gamma_{t}}{\bar{\rho}}} \frac{\partial \xi_{\alpha}^{n}}{\partial x_{i}} d \boldsymbol{W}_{i}{ }^{n} \\
-\frac{\bar{\rho} C_{\phi}}{2 \tau_{s g s}}\left(\xi_{\alpha}^{n}-\widetilde{\phi}_{\alpha}\right) d t+\bar{\rho} \dot{\omega}_{\alpha}^{n}\left(\underline{\xi}^{n}\right) d t,
\end{gathered}
$$

in which $\Gamma_{t}=\mu / \sigma+\mu_{s g s} / \sigma_{s g s}$ is the sum of the molecular and the SGS (sub-grid scale) diffusion coefficient. The Schmidt numbers $\sigma$ and $\sigma_{s g s}$ are assumed a constant value of 0.7 , following Ref. [59]. $d \boldsymbol{W}_{\boldsymbol{i}}{ }^{(n)}$ is the increment of a vector Wiener process that is spatially uniform but different for each field. The SGS-mixing constant $C_{\phi}$ is assigned a value of 2 , following the work of Jones et al. [50,65]. The time-scale of the sub-grid mixing is given as:

$$
\tau_{s g s}=\frac{\bar{\rho} \Delta^{2}}{\mu+\mu_{s g s}}
$$

With increasing number of stochastic fields, the sum of Wiener terms approaches zero. The spatially filtered scalars can be approximated from the ensemble of $N$ stochastic fields: 


$$
\widetilde{\phi}_{\alpha}(\mathbf{x}, t)=\frac{1}{N} \sum_{n=1}^{N} \xi_{\alpha}^{n}(\mathbf{x}, t)
$$

with the statistical error decreasing as $O\left(N^{-1 / 2}\right)$. The computational cost increases with the number of stochastic fields. Based on the previous works for different applications [50,56] and considering the overall computational cost, eight stochastic fields are used in this study. An evaluation of the sensitivity of the Wiener term and the reaction rate term in Eq. (7), as well as the conditional average of the mass fraction of $\mathrm{OH}$ radicals on the flame surface to the number of stochastic fields is presented in Appendix A. It is shown that eight stochastic fields offer an acceptable trade-off between the result-sensitivity and the computational cost.

\section{Burner assembly and computational setups}

The schematic of the swirl burner geometry of Elbaz et al. [56] and the computational domain are illustrated in Fig. 1(a) and (b), respectively. The burner comprises an inner central fuel (methane) jet with a diameter of $d_{f}=4.4 \mathrm{~mm}$, and an annular axial air tube with the diameter ranging from $d_{f o}$ to $d_{A}$, where $d_{f o}=6.4 \mathrm{~mm}$ is the outer diameter of the fuel jet and $d_{A}=27 \mathrm{~mm}$ is the inner diameter of the air tube. In addition, four tangent air jets with a diameter $d_{t}=4.4 \mathrm{~mm}$ is installed in the location $70 \mathrm{~mm}$ upstream of the burner exit plane. The tangential air jets are employed to generate a swirling airflow. This burner configuration was referred to as the burner without the quarl in Elbaz et al. [56].

\section{alt-text: Fig. 1}

Fig. 1

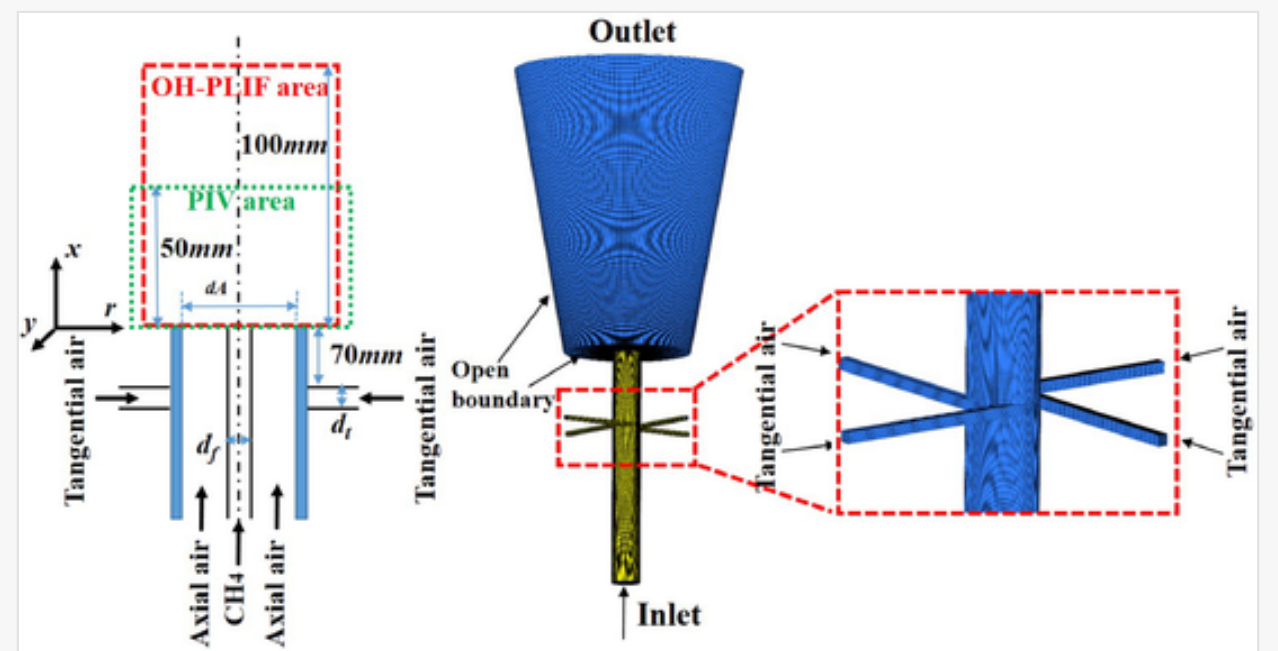

(a) Flames without quarl (Fno)

(b) Computation domain

The swirl burner schematic (a) and the computational domain (b).

The computational domain has been selected based on previous studies of a similar burner [55]. Downstream of the burner, a conical domain is considered in the simulation. The length of the conical domain is $70 d_{f}$, and in the radial direction the computational domain extends from $15 d_{f}$ at the burner exit plane, and $25 d_{f}$ at the downstream boundary. As will be shown in the next section the flow velocity at the outer far-field boundary in the radial direction is essentially zero, which implies that the computational domain is sufficiently large. The minimum grid size is $0.1 \mathrm{~mm}$ in the flame region in the burner near field. The size grows gradually along the axial direction, and the near wall grid size (the first layer grid near the wall) is $0.02 \mathrm{~mm}$ for the wall of the fuel tube 
and $0.04 \mathrm{~mm}$ for the wall of the annular air tube, of which the total cell number is about 6 million. A mesh sensitivity study is carried out using another 2 million hexahedron grids, which will be discussed later. The 6 million mesh is adopted as the baseline mesh in the result analysis.

The boundary conditions were specified as follows. Since the fuel was supplied through a long pipe, a velocity mapping method was employed to determine the inflow boundary condition of the fuel inlet, i.e. the velocity profile at a downstream section was mapped to the fuel inlet. This mapping process was repeated in the entire flame simulations to allow for a temporal evolution of the inlet turbulent flow. When the inlet velocity profile reached that of a statistically stationary fully developed turbulent pipe flow, and the flame also developed to statistically stationary, the results were used to compute statistical averages for the analysis of local extinction and re-ignition. For the air inlets, a top-hat velocity profile is assumed since the tangential flow from the four air jets generates a strong turbulence field that is insensitive to the actual velocity profile of the air inlets. At the wall boundaries, a non-slip zero velocity condition is applied and zero-gradient for the pressure is assumed. As the flame located in an open environment, for an open boundary (cf. Fig. 1) and the outlet, the total pressure condition [66] and zero-gradient for the velocity is adopted, allowing the free entrainment of the ambient air into the flame. The fuel and air temperature is set at $298 \mathrm{~K}$, and the combustor pressure is $1 \mathrm{~atm}$.

The solver is based on OpenFoam libraries [66]. A second order filtered-linear implicit scheme is utilized for the spatial discretization, and the second-order backward Euler scheme is employed for the temporal integration. The Pressure Implicit with Splitting of Operator (PISO) algorithm is used for the pressure-velocity coupling. The solver has been validated and applied to studies of turbulent non-premixed flames [21,55] and turbulent premixed flames $[60,67]$. Considering the high computational cost required by the present LES-PDF model, a skeletal chemical mechanism with 16 species and 35 reactions developed by Smooke [68] is adopted to model chemical reactions. According to the computation of one-dimensional (1D) counterflow methane/air diffusion flame at $1 \mathrm{~atm}$ pressure and $298 \mathrm{~K}$ reactants temperature, a quenching scalar dissipation rate of $35 \mathrm{~s}^{-1}$ is predicted with the current skeletal mechanism, which is comparable to the corresponding value of $33 \mathrm{~s}^{-1}$ predicted using GRI3.0 mechanism [69]. The laminar flame speed calculated using the Smooke mechanism is $43 \mathrm{~cm} / \mathrm{s}$, which is slightly higher than the value of $39 \mathrm{~cm} / \mathrm{s}$ calculated using the GRI3.0 mechanism. These differences are expected to be not affecting the qualitative analysis of the results.

The conditions of the studied flames are listed in Table 1, where the bulk flow velocity of the fuel stream $U_{f}$, through the central fuel jet varies from $8.7 \mathrm{~m} / \mathrm{s}$ to $55 \mathrm{~m} / \mathrm{s}$, while the airflow is kept constant. $U_{a}$ is the axial air velocity through the annular tube, $U_{t}$ is the tangential air velocity through four tangential air tubes, and $U_{e}$ is the bulk flow velocity of the air stream at the burner exit. A geometric swirl number [70], $S_{g}$, is kept constant at 12 with varying fuel jet velocities. The geometric swirl number is defined as follows,

$$
S_{g}=\frac{\pi r_{0} d_{A}}{2 A_{t}}\left(\frac{m_{\theta}}{m_{\theta}+m_{A}}\right)^{2}
$$

where $r_{0}$ is the radius of the air tube where the tangential air is injected (here $\left.r_{0}=d_{f} / 2\right) ; m_{\theta}$ and $m_{A}$ are the tangential and axial air flow rates, respectively. $A_{t}$ is the area of the four tangential air inlets. 
(i) The table layout displayed in this section is not how it will appear in the final version. The representation below is solely purposed for providing corrections to the table. To preview the actual presentation of the table, please view the Proof.

Key parameters of the studied flames. "“.'Fno" stands for the burner without the quarl [56].

\begin{tabular}{|c|c|c|c|c|c|c|}
\hline Cases & $U_{f}[\mathrm{~m} / \mathrm{s}]$ & $U_{a}[\mathrm{~m} / \mathrm{s}]$ & $U_{t}[\mathrm{~m} / \mathrm{s}]$ & $U_{e}[\mathrm{~m} / \mathrm{s}]$ & $S_{g}$ & $S$ \\
\hline Fno8.7 & 8.7 & \multirow{2}{*}{0.65} & \multirow{2}{*}{37.9} & \multirow{2}{*}{4.85} & \multirow{2}{*}{12} & 0.909 \\
\hline Fno33 & 33 & & & & & 0.820 \\
\hline Fno55 & 55 & & & & & 0.574 \\
\hline
\end{tabular}

The geometric swirl number defined in Eq. (10) denotes the swirl level of the airflow only. Masri et al. [5,12] quantified the swirl level of the Sydney swirl flames using a different airflow swirl number (defined as the ratio of the tangential velocity to that of the axial velocity at the exit of the airflow annulus). It should be noted that these airflow swirl numbers do not represent the overall swirling flow effect of the burner since the fuel flow is excluded. An effective swirl number accounting for the momentum of the entire inflow, from both the air inlet and the fuel inlet, can be defined as follows [71],

$$
S=\frac{\int_{0}^{d_{A} / 2} U_{t} U_{a} r^{2} d r}{\left(d_{A} / 2\right) \int_{0}^{d_{A} / 2} U_{a}^{2} r d r}
$$

where $U_{t}$ and $U_{a}$ denote the tangential velocity and the axial velocity components at the burner exit plane, respectively. This swirl number decreases with the increasing central fuel jet velocities, Table 1. Consequently, the effects of swirl flow on the flame become weaker as the fuel jet velocity increases.

\section{Results and discussion}

\subsection{Flow field and flame structures}

Figure 2 (a), (c), and (d) shows a comparison of the mean axial velocities and the RMS axial velocities fluctuations obtained from the PIV measurements and the LES at different flame heights along the radial direction for three cases. Figure 2(b) compares the mean tangential velocity from PIV and LES at the corresponding flame heights along the radial direction for case Fno8.7. The time-averaged LES results are obtained with 10 characteristic flow-through times. The mean axial velocities and the RMS axial velocity fluctuations predicted in LES are in close agreement with the experimental data, indicating that the overall flow fields are well predicted using the LES-ESF method for all three flames. The PDF-LES can also predict the tangential velocities reasonably well. Furthermore, it can be seen that the LES results for the Fno8.7 flame from both meshes yield an almost identical mean flow velocity, revealing that the results are relatively insensitive to the grid size with the current grid resolution. There is a minor difference in the peak mean axial velocity and the peak RMS axial velocity fluctuation on the centerline predicted from the LES using both meshes. As the refined 
mesh with 6 million cells gives a slightly better agreement with the experiments, it is used in the remaining LES studies.

alt-text: Fig. 2

Fig. 2
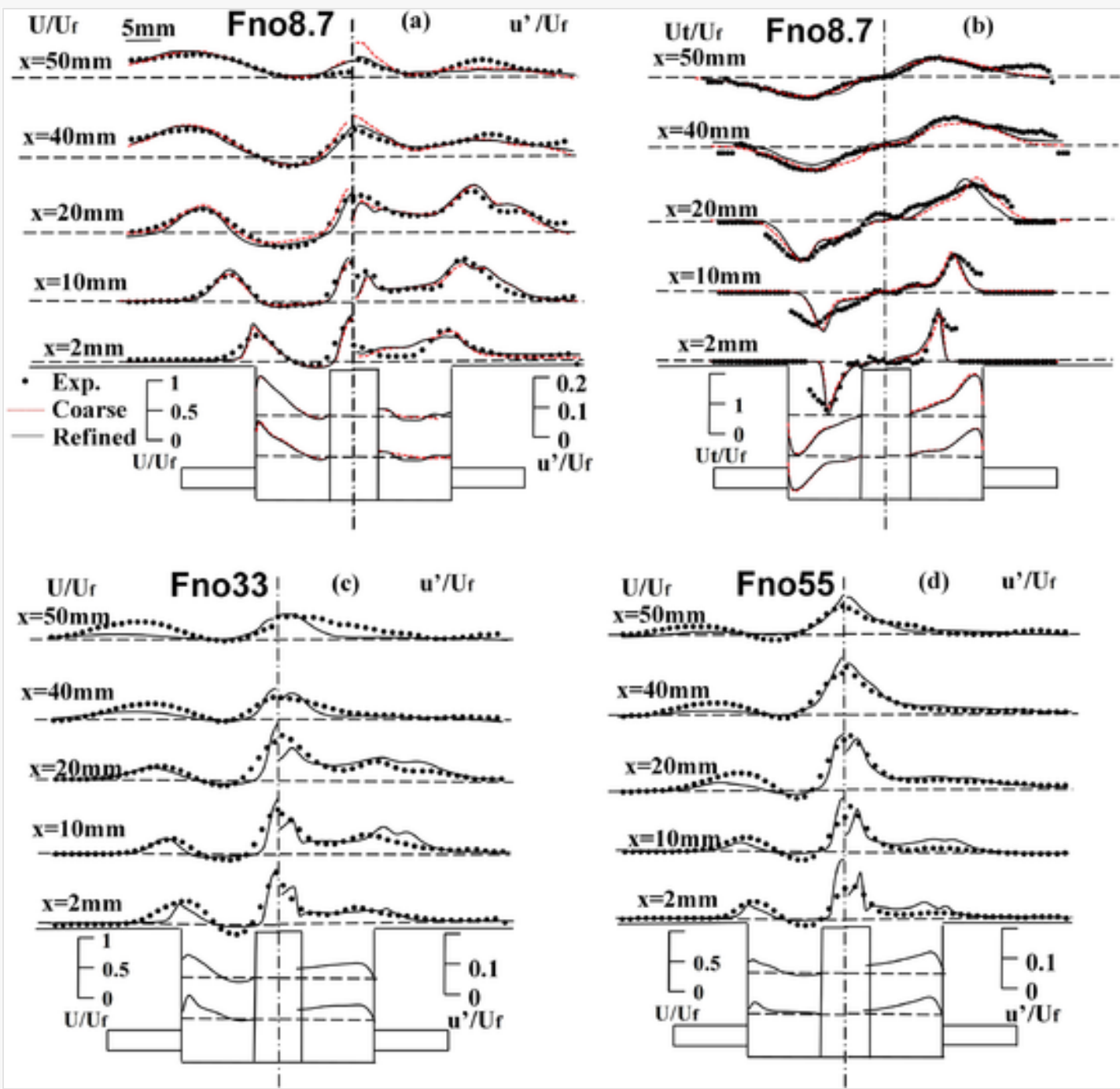

Mean axial velocities and RMS axial velocities fluctuations from PIV (symbols) and LES (lines) for flame cases Fno8.7 (a), Fno33 (c), and Fno55 (d); and mean tangential velocity profiles from PIV (symbols) and LES (lines) for Fno8.7 (b). Coarse mesh: 2 million cells, refined mesh: 6 million cells.

From the mean axial velocity (normalized by the mean fuel jet velocity, $U / U_{f}$ ), two peaks of positive mean axial velocity can be found along the radial coordinate, and in between the two peaks a negative axial velocity can be found. This flow structure indicates the existence of a swirl induced Internal Recirculation Zone (IRZ) for all three flames. The velocity peak on the centerline is due to the fuel jet; the velocity peak in the outer shear layer of the IRZ is due to the swirling airflow. Both peaks decrease along downstream direction, with the peak at the outer shear layer shifting outward in the radial direction, owing to the expansion of the swirling airflow. With increasing fuel jet velocities, the second peak becomes relatively weaker (compared with the fuel jet velocity), implying that the fuel jet flow becomes more dominant; however, the structure of IRZ remains similar in all flame cases.

The RMS velocity pulsation profiles $\left(u^{\prime}\right.$ normalized by $\left.U_{f}\right)$ from the LES and the measurements are also in good agreement with each other for all three flame cases, although a small shift of the peak $u^{\prime} / U_{f}$ off the centerline is found for the Fno33 and Fno55 cases near the burner exit. This difference could be attributed partly 
to the open boundary as shown in Fig. 1(b), being selected relatively close to the burner exit, especially for the higher jet velocities. It is expected that a larger computational domain could give better results but the computational cost would be higher. Moreover, the discrepancy between the LES results and the experiments could also be due to the assumption of adiabatic condition in LES, which may cause the over-prediction of flame temperature and under-prediction of density. Judging the overall prediction of the mean and RMS velocities, the current numerical results are considered to be acceptable.

Figure 3 shows the instantaneous $\mathrm{OH}$ distributions from the experiments and LES for the three flames. The low fuel jet velocity flame Fno8.7 $\left(U_{f}=8.7 \mathrm{~m} / \mathrm{s}\right)$ shows a continuous $\mathrm{OH}$ field starting from the burner extending to $x \sim 100 \mathrm{~mm}$, which indicates that the flame is burner-attached without local extinction. The $\mathrm{OH}$ layer coincides with the iso-line of stoichiometric mixture fraction, indicating that the combustion process is a classical diffusion flame. In the Fno33 flame case, the instantaneous OH PLIF field exhibits isolated flame holes and flame kernels in the near burner region $(x \sim 20-60 \mathrm{~mm})$, whereas the LES predicted OH mass fraction shows also flame kernels separated by the flame holes. The flame kernels are around the iso-line of the stoichiometric mixture fraction. With further increase of the fuel jet velocity to $U_{f}=55 \mathrm{~m} / \mathrm{s}$, the instantaneous OH PLIF field shows a discontinuous $\mathrm{OH}$ distribution, with a small region of $\mathrm{OH}$ in the proximity of the burner exit $(x \sim 0-10 \mathrm{~mm})$, followed by a region where $\mathrm{OH}$ is absent $(x \sim 20-50 \mathrm{~mm})$ denoting local flame extinction, and further downstream a continuous $\mathrm{OH}$ field $(x>50 \mathrm{~mm})$ denoting re-ignition, cf. Fig. 3(c). The LES predicted OH mass fraction shows a similar distribution. Again, the $\mathrm{OH}$ layer overlaps with the stoichiometric mixture fraction. As will be shown later, the lower flame part in Fno33 and Fno55 is stabilized by the swirl induced reversed flow (cf. Fig. 2), which brings the hot products and reactants upstream into the airflow tube.

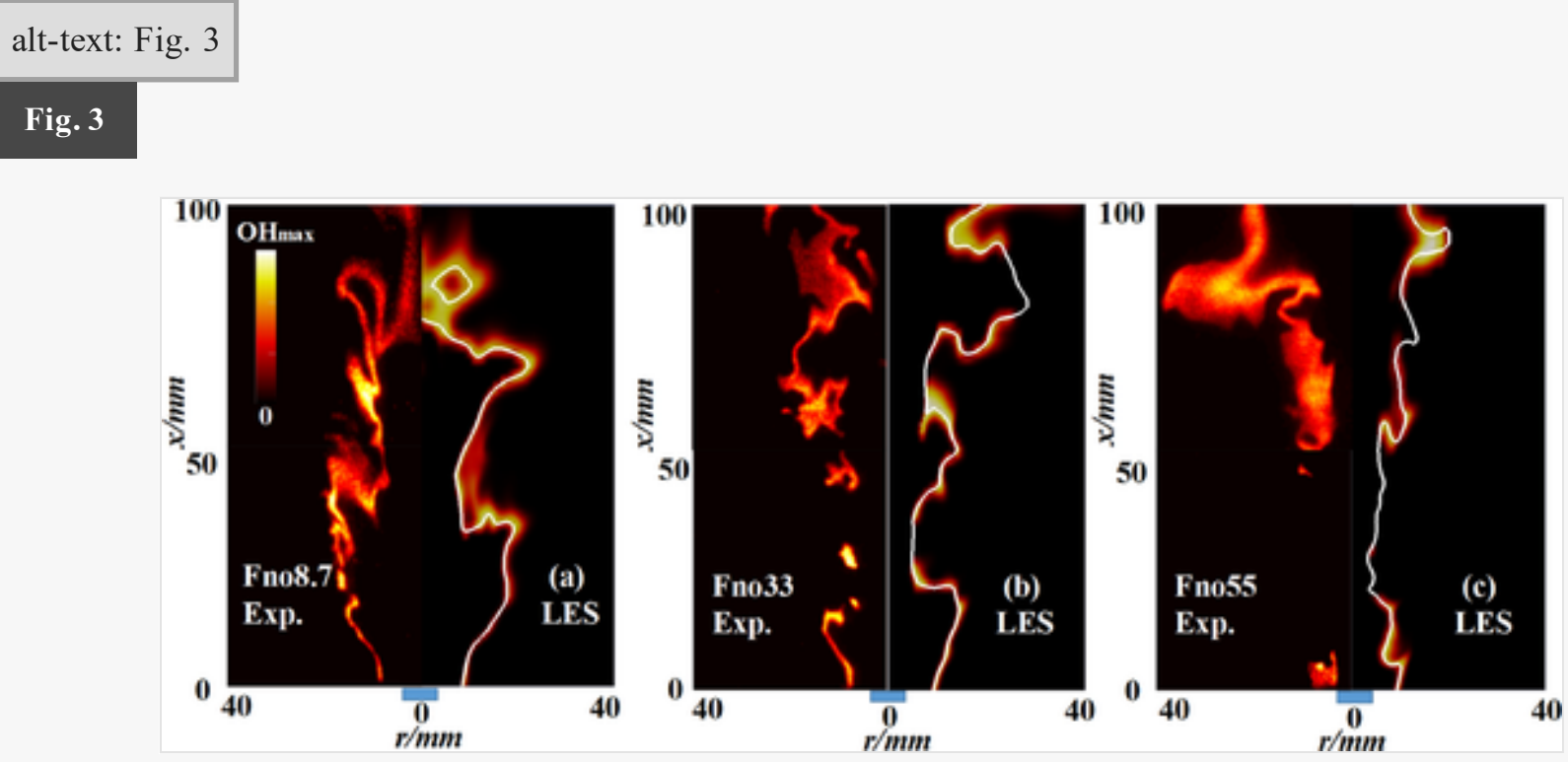

Instantaneous distribution of OH PLIF signal intensity and LES predicted OH mass fraction for three flame cases. The white line represents the iso-line of the stoichiometric mixture fraction, and the small box marks the fuel tube.

The mean $\mathrm{OH}$ field displayed in Fig. 4 shows a rather thin layer of OH PLIF field near the burner exit $(x \sim 0$ $15 \mathrm{~mm}$ ) in the low-speed flame Fno8.7, indicating that the local flame is rather steady and nearly laminar. Further downstream ( $x \sim 20-50 \mathrm{~mm}$ ), the mean $\mathrm{OH}$ layer is much broader, corresponding to the strong fluctuation of the wrinkled $\mathrm{OH}$ layer (cf. Fig. 3(a)). The mean $\mathrm{OH}$ field of the Fno33 flame shows a broader near-burner mean $\mathrm{OH}$ layer, followed by a low $\mathrm{OH}$ intensity region $(x \sim 25-40 \mathrm{~mm})$ due to local extinction (Fig. 4(b)) and finally a broad region with high $\mathrm{OH}$ intensity $(x \sim 50-100 \mathrm{~mm}$, Fig. 4(c)). The mean $\mathrm{OH}$ intensity downstream of the burner exit $(x \sim 0-50 \mathrm{~mm})$ in the high-velocity flame Fno55 is very low due to the strong local extinction 
downstream the burner. Further downstream, the mean $\mathrm{OH}$ layer is broad, with the width of the layer expanding to the entire window shown in Fig. 4(d). Though the $\mathrm{OH}$ fields observed in experiments are not so smooth and the comparisons are qualitative, it is shown that LES can simulate reasonably well the mean $\mathrm{OH}$ field observed in the experiments.

\section{alt-text: Fig. 4 \\ Fig. 4}

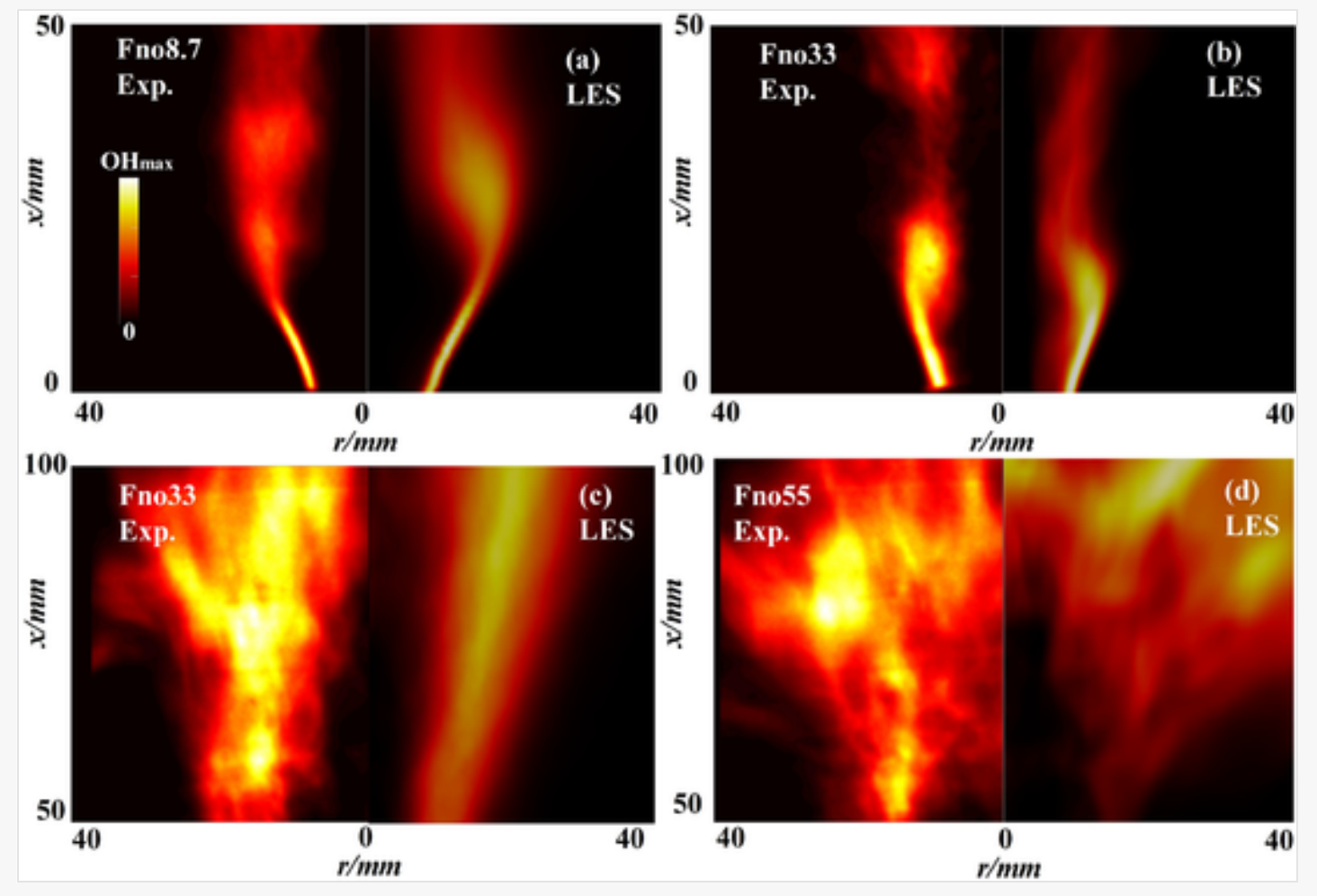

Mean OH PLIF signal intensity and LES predicted mean mass fraction of $\mathrm{OH}$ radicals for the three flame cases.

To characterize the local extinction, it is useful to quantify the extent of local extinction using a quenching probability [72]. Different criteria have been discussed in the literature to define a locally quenched region. Masri et al. [5,12] proposed to use a temperature-based criterion (burning index) $B_{I T}=\left(T-T_{0}\right) /\left(T_{b}-T_{0}\right)$, where $T_{0}$ is the ambient temperature and $T_{b}$ is the temperature of the stoichiometric mixture at a low strain rate condition. $B_{I T}$ close to 1 indicates stable burning while close to zero indicates extinction. Hewson and Kerstein [72] discussed two other criteria, one temperature-based and one radical based, i.e., with the temperature of the stoichiometric mixture below $1000 \mathrm{~K}$ or the radical concentration close to zero indicating local extinction, respectively. The radical based criterion and $T<1000 \mathrm{~K}$ criterion were shown to yield similar results. The probability of $P\left(T<1000 \mathrm{~K}\right.$ ) is also similar to $1-B_{I T}$ (burning index) [72]. In the present experiments, the temperature data were not available, and we used the $\mathrm{OH}$ radicals based criterion of Hewson and Kerstein [72] as the measure of local extinction and re-ignition.

Figure 5 shows the quenching probability obtained from the OH PLIF experiments and the OH mass fraction from LES along the flame height for the Fno33 and Fno55 cases. In both cases, the LES predicted a low quenching probability in the near burner region $(x<10-20 \mathrm{~mm})$, followed by a high quenching probability around $x \sim 30-50 \mathrm{~mm}$ for Fno33, and $x \sim 20-30 \mathrm{~mm}$ for Fno55. This trend agrees reasonably well with the experiments. The LES predicted quenching probability agrees better with the experiments for the high speed flame case Fno55, which also exhibits a higher quenching probability than the case Fno33. For the Fno33 case, 
the LES predicted a lower quenching probability in the region of $x \sim 25-40 \mathrm{~mm}$ than the experiments, which can also be seen in the mean $\mathrm{OH}$ field shown in Fig. 4(b). This discrepancy may be partly due to the uncertainties in the chemical kinetic mechanism used. In the near burner region the difference between the LES predicted quenching probability and the experimental one is larger, due to the highly transient nature of the local extinction event in this region where the onset of local extinction starts to occur, cf. Fig. 3.

\section{alt-text: Fig. 5}

\section{Fig. 5}
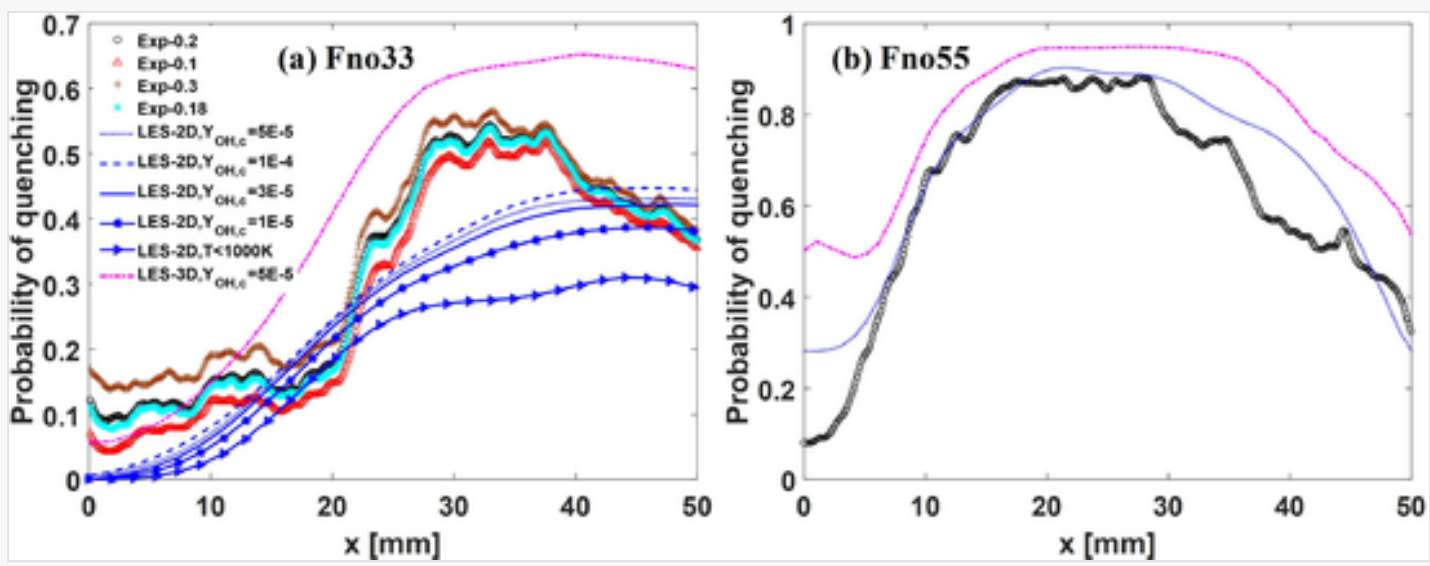

Quenching probability along the flame height for (a) Fno33 and (b) Fno55, determined from 2D OH PLIF experiments and 2D and 3D OH mass fractions from LES, and 2D temperature from LES. Exp $-\alpha: 2 \mathrm{D}$ OH PLIF data with a binarization threshold value of $\alpha$.

To compute the quenching probability, $500 \mathrm{OH}$ PLIF images were post-processed according to the following procedure. First, the left half of the OH PLIF image, which has a slightly better signal-to-noise ratio (SNR), was binarized, i.e., the burning region being set to a value of 1 and the quenching region a value of 0 , according to a threshold value that depends on the SNR [3,19]. Then, the quenching probability is calculated as $P_{q}(x)=(1 / N) \sum_{i}^{N} s_{i}(x)$, where $N$ is the total number of samples used in the calculation and $s_{i}$ is an quenching index ( 0 denotes burning and 1 quenching). At a given flame height $(x)$, if all binarized $\mathrm{OH}$ signal in a PLIF image sample is zero within a spatial interval of $0.15 \mathrm{~mm}$ in the axial direction, the quenching index at the given flame height is set as $s_{i}(x)=1$. For LES results, the quenching probability is determined from $\mathrm{OH}$ mass fraction within 5 flow-through times following a similar procedure.

The sensitivity of quenching probability to the binarization threshold of $\mathrm{OH}$ signal intensity was examined. As seen in Fig. 5(a), the results are relatively insensitive to the threshold when the value of 0.2 was chosen, although in the near burner region the sensitivity is higher, due to the highly transient nature of the local extinction event in this region. Since the SNR of OH PLIF is about 4.6, the signal is noisy when the normalized OH PLIF signal is below the value of $1 / \mathrm{SNR}$, i.e., around 0.2. As the OH PLIF images are two dimensional, a similar two dimensional analysis was performed when post-processing the LES results, the results being denoted as "“LES2D”. The critical threshold in LES used for the determination of quenching is $Y_{O H, c}$. When $Y_{O H}<Y_{O H, c}$, the flame is considered to be quenched, with $s_{i}$ setting a value of 1 . Four threshold values were tested as shown in Fig. 5(a), which reveals that the results are relatively insensitive to $Y_{O H, c}$ when $Y_{O H, c}$ is about $5 \times 10^{-5}$, which is about $1 \%$ of the maximal $\mathrm{OH}$ mass fraction in the field. In the Fno55 flame case, $Y_{O H, c}=5 \times 10^{-5}$ was therefore used for the calculation of quenching probability. For comparison, a critical temperature $1000 \mathrm{~K}$ was used as another criterion for local extinction. It is seen that the temperature criterion yields a similar trend of quenching 
probability as that of the $\mathrm{OH}$ criterion, although $T<1000 \mathrm{~K}$ is a slightly more relaxed criterion for local extinction as compared with the $\mathrm{OH}$ radical criterion. In Fig. 5(a), the profile "“LES-3D” shows the quenching probability obtained from the 3D LES results following the same procedure as that in the 2D analysis. It appears that for flame Fno33, the 2D and 3D results differ considerably, indicating a highly 3D local flame hole structure in this flame. For flame Fno55, the difference between 2D and 3D results is relatively small, due to the high quenching probability and larger flame holes, cf. Fig. 3. The larger difference between the 2D and 3D results in the near burner region of flame Fno55 is due to the highly transient nature of the local extinction events in the region.

Figure 6 shows the LES predicted the mean axial velocity, the mean temperature, mean mass fractions of $\mathrm{CH}_{2} \mathrm{O}$, $\mathrm{OH}, \mathrm{HCO}$, and the mean HRR (heat release rate), the mean mixture fraction $Z$, and the mean scalar dissipation rate $\chi$, computed using LES data collected within 10 characteristic flow-through times with a further spatially circumferential averaging. The scalar dissipation rate calculated in LES used the following equation [73,74]:

$$
\chi=2 \Gamma_{t} \nabla \widetilde{Z} \cdot \nabla \widetilde{Z}
$$

In all flame cases, the internal recirculation zone (enclosed by the green lines) is shown to extend into the airflow tube, upstream the exit of the fuel jet. The reversed flow transports the fuel into the airflow tube creating a suitable condition for mixing. The scalar dissipation rate around the stoichiometric mixture fraction in the recirculation zone is much lower than the referenced value for quenching of a steady laminar flame $\left(\chi_{q} \approx 35 \mathrm{~s}^{-1}\right.$ for the current chemical kinetic mechanism), which is the reason that the present flame is stabilized in the airflow tube. Several authors have compared the quenching scalar dissipation rate in laminar unsteady flames [75] and turbulent flames $[18,42]$ with that of steady laminar flames. It has been shown that quenching in an unsteady laminar vortical flow or in a turbulent flame occurred at a scalar dissipation rate greater than the quenching scalar dissipation rate of a steady laminar flame. From the distributions of HRR, HCO, OH, and temperature, it appears that the flame is stabilized in the recirculation zone around the stoichiometric mixture fraction in all flame cases. The flame inside the recirculation zone is a burner attached diffusion flame.

alt-text: Fig. 6

Fig. 6 
The onset of the IRZ is a result of the vortex breakdown of the swirling airflow, which is sensitive to the effective swirl number. In the inner shear layer adjacent to the fuel jet stream, the scalar dissipation rate is high. In the outer shear layer of the IRZ adjacent to the swirling airflow stream, the mixture is close to stoichiometric and the scalar dissipation rate is low. This allows for the diffusion flame to be stabilized in the IRZ. The size of the recirculation zone downstream the fuel jet decreases with the increasing fuel jet velocity due to the increasing axial momentum flux, which gives rise to a decreasing swirl number, cf. Table 1. With the increasing central fuel jet velocity and the decreasing size of recirculation zone, the iso-line of the stoichiometric mixture fraction (where the diffusion flame is located) moves closer to the inner layer of the recirculation zone where the scalar dissipation rate is high, and the flame becomes weaker, eventually leading to local extinction.

In the Sydney turbulent bluff body and swirling flames measured by Masri et al. [5,12], similar local extinction locations ("neck" regions) have been reported. In the Sydney burner, a large bluff body was placed in between the fuel nozzle and the air annulus, whereas the present one has no such bluff body. This leads to a significantly different mixing field and different quenching mechanism. In the case with a bluff body, the mixing of the fuel and the air in the recirculation zone downstream the bluff body leads to a significantly smaller gradient of mixture fraction and a less severe local extinction. Masri et al. [12] found that the local extinction was originated from outer radial locations closer to the coflow air rather than the fuel jet, where high tangential shear stresses tend to exist. In the present flames, the scalar dissipation rate is high in the inner boundary of the recirculation zone adjacent to the fuel flow stream, owing to the high gradient of mixture fraction. Thus, local extinction in the present flames is due to the high scalar dissipation rate in the inner boundary layer adjacent to the fuel jet.

It is interesting to note that for flames Fno33 and $\mathrm{Fno} 55 \mathrm{CH}_{2} \mathrm{O}, \mathrm{HCO}$, and $\mathrm{HRR}$ are found in rather thin layer in the recirculation zone, whereas downstream of the recirculation zone, the mean $\mathrm{CH}_{2} \mathrm{O}, \mathrm{HCO}$, and temperature are found in rather broad and fuel-rich regions. As will be shown later this is due to the combustion of the fuelrich branch of the tribrachial flame structure in the region downstream the recirculation zone.

To examine the statistics of the flames, Fig. 7 shows the Joint Probability Density Function (JPDF) of temperature and mixture fraction for flames Fno33 and Fno55 at three flame heights. The JPDF is computed using the LES data collected within a flow-through time. For a given mixture fraction the highest temperature that could be found in the domain is that of the diffusion flame at a low scalar dissipation rate. At $x=25 \mathrm{~mm}$, the temperature at stoichiometric mixture fraction distributes in the range of $1000 \mathrm{~K}<T<2100 \mathrm{~K}$ and the mean temperature is rather close to the highest temperature at a given mixture fraction. This is a result of the high probability of having a diffusion flame under low scalar dissipation rate at the flame height. As will be discussed later, there are also small flame holes at this low flame height, which is responsible for the JPDF of low temperatures at $Z_{s t}$. At $x=50 \mathrm{~mm}$, the PDF of having a temperature at $Z_{s t}$ lower than $1000 \mathrm{~K}$ is much higher, which gives rise to a mean temperature significantly lower than the peak flame temperature of a diffusion flame. From the results discussed earlier, this is a result of the significantly higher probability of having flame holes at this flame height, cf. the quenching probability diagram in Fig. 5. At further downstream, $x=75 \mathrm{~mm}$, the mean flame temperature is rather close to the highest temperature, indicating that the probability of having flame holes is low at this flame height. There is a noticeably high PDF of temperature lower than the diffusion flame one in the fuel-rich mixture, e.g., $Z \sim 0.3-0.5$. This corresponds to the mixture in the fuel-rich region of the flame hole discussed earlier. 
lower than $\chi_{q}$, a flame hole can be re-ignited. The size of flame hole $\mathrm{A}$ is approximately (in diameter) $5 \mathrm{~mm}$, and shrinks at a speed around $5 \sim 10 \mathrm{~m} / \mathrm{s}$. This speed is significantly higher than the laminar flame speed in a methane/air stoichiometric mixture.

\section{alt-text: Fig. 8}

\section{Fig. 8}

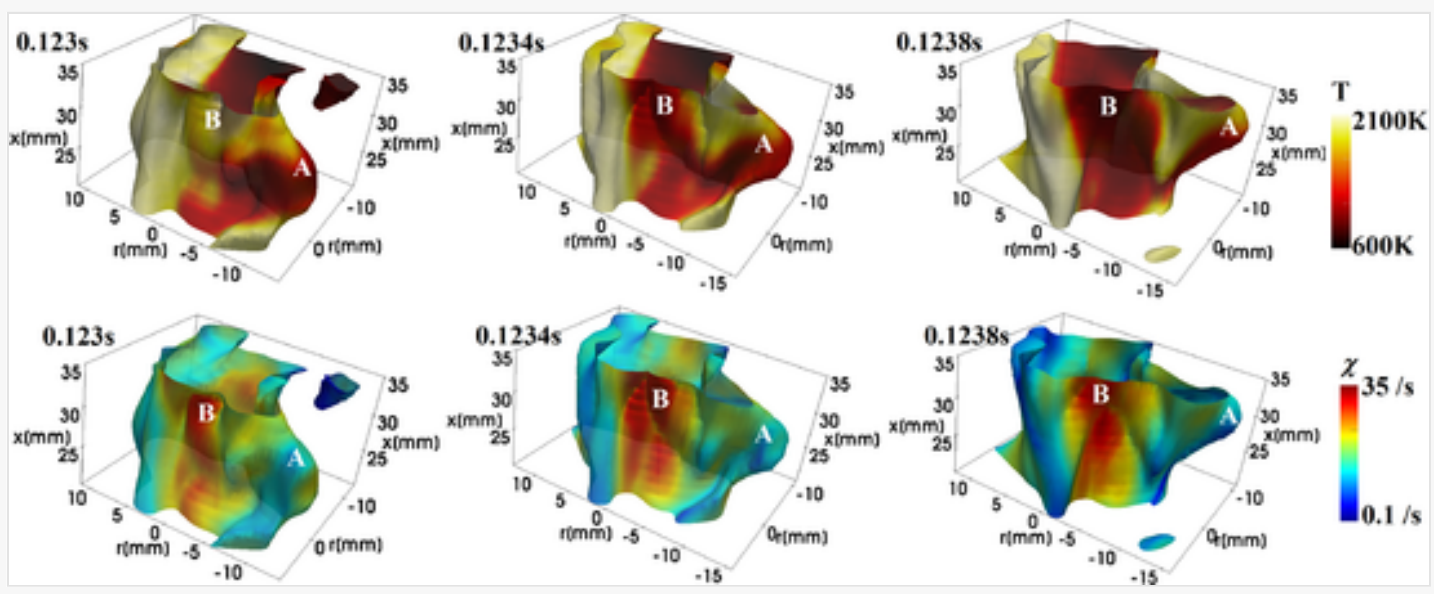

$T$ and $\chi$ contours on the 3D iso-surface of $Z_{s t}$ for flame Fno33 for a time interval $0.123 \mathrm{~s}<t<0.124 \mathrm{~s} . t=0$ denotes an arbitrary time when the flame is at the statistically stationary state. Region-A shows a re-ignition event and region-B indicates a local extinction event.

Statistical analyses of the flame holes shown in Fig. 8 are performed using the JPDF of temperature and scalar dissipation rate, cf. Fig. 9(a). The sample data are collected on the iso-surface of $Z_{s t}$ for the region $x=25 \mathrm{~mm} \pm 2.5 \mathrm{~mm}$ of flame Fno33, within a time interval of $10 \mathrm{~ms}$. As seen, there are two temperature branches of high JPDF, a high-T branch around $2000 \mathrm{~K}$ and a low-T branch around $1000 \mathrm{~K}$. The high-T branch represents the stable diffusion flame state and it is found under low scalar dissipation rate, $\chi<10 \mathrm{~s}^{-1}$. The low-T branch represents the flame holes, which is found under the condition of $\chi>0.1 \mathrm{~s}^{-1}$. Quenching and re-ignition states are found in between the high-T and the low-T branches. Significantly high JPDF of quenching and re-ignition states can be found for moderate scalar dissipation rate, i.e., $0.1 \mathrm{~s}^{-1}<\chi<\chi_{q} \approx 35 \mathrm{~s}^{-1}$. Since $\chi=\chi_{q}$ represents the condition of quenching of a steady laminar flame, it is clear that for turbulent flames local extinction can occur at much lower values of $\chi$, while under $\chi>\chi_{q}$ the flame is quenched. Thus, $\chi>\chi_{q}$ is a sufficient but not necessary condition for local quenching in the present turbulent flames. 
Figure 9 (b) shows that the time scale for local extinction, e.g., one of the quenching manifolds of $\chi>35 \mathrm{~s}^{-1}$, is about $0.9 \mathrm{~ms}$. The re-ignition time as shown by the ignition-manifolds (with temperature increasing with time) is on the same order of magnitude, Fig. 9(c). The extinction/re-ignition time may be compared with the diffusion time of an unsteady laminar flamelet. Mauß et al. [76] estimated the diffusion time scale of an unsteady laminar flamelet. By balancing the unsteady term and the diffusive term of the unsteady laminar flamelet equation, it was found that

$$
t_{d} \sim Z_{s t}^{2} / \chi_{q}
$$

where $t_{d}$ was considered to be the characteristic time scale of flamelet extinction [76]. The diffusion/extinction time of flamelet under the present flame conditions is $t_{d} \sim 0.055^{2} / 35=0.086 \mathrm{~ms}$, which is an order of magnitude shorter than the extinction time or re-ignition in the flame Fno33. This result is consistent with the the DNS result of turbulent non-premixed ethylene jet flames by Lignell et al. [42], where it was found that the local extinction time is around $0.1 \mathrm{~ms}$ for the case with the highest nitrogen dilution in the fuel and oxygen streams. The diffusion/extinction time of flamelet was estimated to be $t_{d} \approx 0.012 \mathrm{~ms}$, which is also an order of magnitude shorter than its extinction time.

The local extinction and re-ignition process of a flame hole can be described as follows. First, at high values of scalar dissipation rate, the rate of air mixing to the flame leads to a decrease of the local temperature and a decrease in the local reactivity. Eventually, the local flame is quenched. Second, if a flame hole is in a region of a low scalar dissipation rate, the hot gas and radicals from the surrounding flame are transported to the flame hole by turbulent eddies, leading to the increase of the local heat release and temperature. Eventually, the flame hole is re-ignited. The re-ignition process is consistent with the turbulent flame folding mechanism discussed in the literature [13-17].

\subsection{Local flame extinction and re-ignition in flame Fno33}

When local flame extinction occurs in a large region, the extinction and re-ignition processes are likely different from that of a small flame hole discussed earlier, since the turbulent flame folding mechanism of hot gas and radicals transport from the surrounding flame to the flame hole is absent. Figure 10 shows an instantaneous field of HRR, temperature, scalar dissipation rate, and mass fractions of $\mathrm{OH}, \mathrm{H}_{2}, \mathrm{HO}_{2}$ and $\mathrm{CH}_{4}$, and the reaction rates of $\mathrm{H}_{2}$ and $\mathrm{HO}_{2}$ for flame Fno33. The iso-lines of the stoichiometric mixture fraction separate the fuel-rich region around the centerline of the burner and the fuel-lean region outside. As discussed earlier, the swirling airflow induced a flow recirculation in the air tube, which enables the transport of fuel into the air tube. The low scalar dissipation rate in the air tube allows for a stable flame in the region. Figure 10 shows a two-layer HRR distribution in the air tube, one in the fuel-lean mixture and one along the iso-surface of stoichiometric mixture fraction. From the individual reaction rate along line B in the air tube (cf., the HRR field), it is found that the HRR layer in the stoichiometric mixture is mainly dominant by the reactions consuming $\mathrm{OH}$ radicals, i.e., $\mathrm{H}_{2}+$ $\mathrm{OH}=\mathrm{H}_{2} \mathrm{O}+\mathrm{H}$ (denoted hereafter as $\mathrm{R}$, Table 2) and $\mathrm{OH}+\mathrm{OH}=\mathrm{H}_{2} \mathrm{O}+\mathrm{O}(\mathrm{R} 7)$. The HRR of the fuel-lean mixture comes mainly from the recombination reaction of $\mathrm{H}$ radicals, $\mathrm{H}+\mathrm{O}_{2}+\mathrm{M}=\mathrm{HO}_{2}+\mathrm{M}$ (R9). 


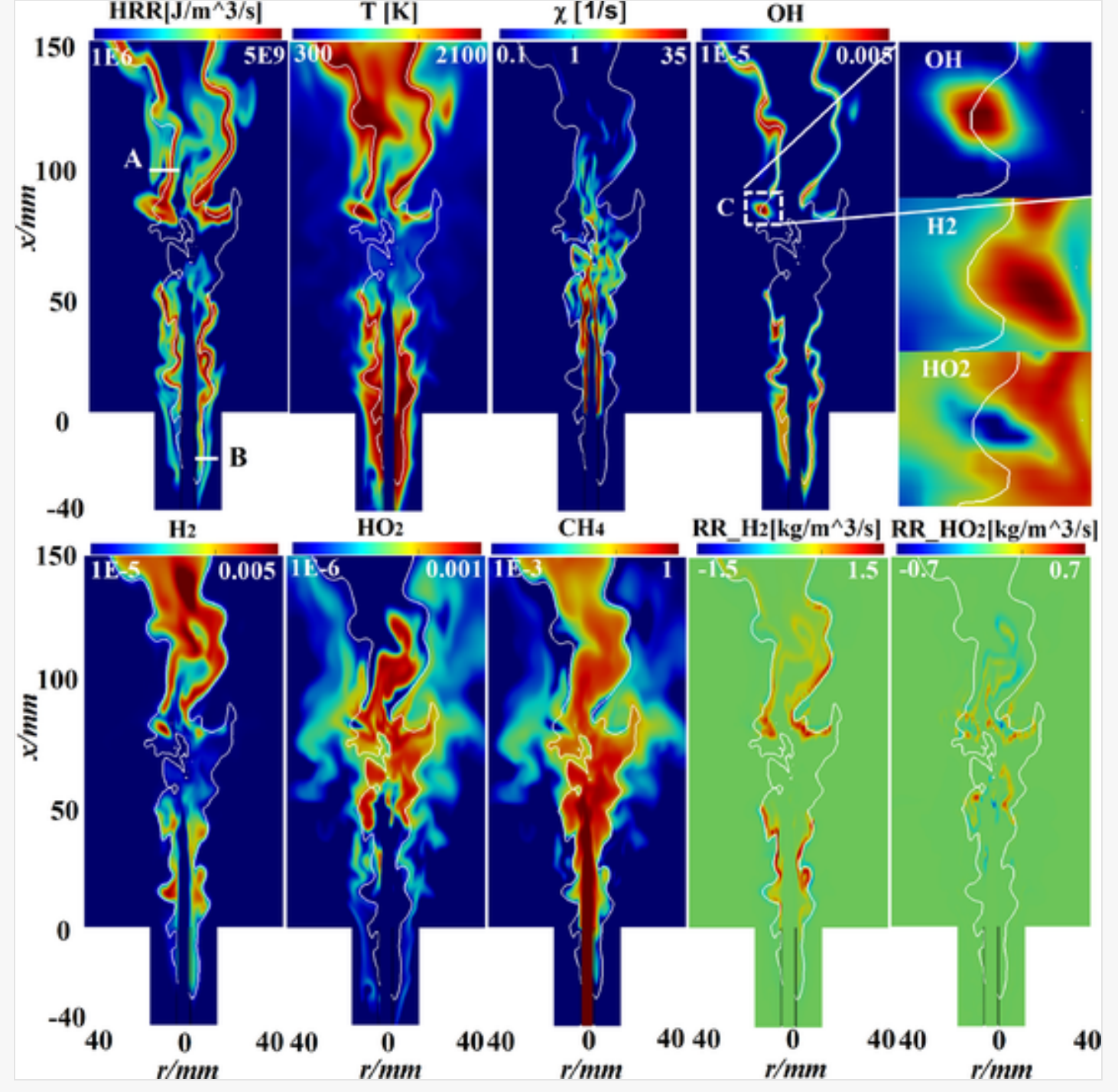

Instantaneous distributions of HRR, temperature, scalar dissipation rate, mass fractions of $\mathrm{OH}_{2} \mathrm{H}_{2}, \mathrm{HO}_{2}$, and $\mathrm{CH}_{4}$, and reaction rates of $\mathrm{H}_{2}$ and $\mathrm{HO}_{2}$ for flame Fno33. HRR, $\chi, \mathrm{HO}_{2}$, and $\mathrm{CH}_{4}$ are shown in log-scale and the white lines denote the stoichiometric mixture fraction $Z_{S t}$.

alt-text: Table 2

Table 2

(i) The table layout displayed in this section is not how it will appear in the final version. The representation below is solely purposed for providing corrections to the table. To preview the actual presentation of the table, please view the Proof.

Key reactions in the Smooke mechanism [68] contributing to the formation of flame holes and to the edge flame propagation.

\begin{tabular}{|l|l|l|l|}
\hline $\mathrm{R} 1$ & $\mathrm{H}+\mathrm{O}_{2}=\mathrm{O}+\mathrm{OH}$ & $\mathrm{R} 5$ & $\mathrm{H}_{2}+\mathrm{OH}=\mathrm{H}_{2} \mathrm{O}+\mathrm{H}$ \\
\hline $\mathrm{R} 7$ & $\mathrm{OH}+\mathrm{OH}=\mathrm{H}_{2} \mathrm{O}+\mathrm{O}$ & $\mathrm{R} 9$ & $\mathrm{H}+\mathrm{O}_{2}+\mathrm{M}=\mathrm{HO}_{2}+\mathrm{M}$ \\
\hline $\mathrm{R} 10$ & $\mathrm{HO}_{2}+\mathrm{H}=\mathrm{OH}+\mathrm{OH}$ & $\mathrm{R} 15$ & $\mathrm{CH}_{4}=\mathrm{CH}_{3}+\mathrm{H}$ \\
\hline $\mathrm{R} 25$ & $\mathrm{HCO}+\mathrm{M}=\mathrm{CO}+\mathrm{H}+\mathrm{M}$ & $\mathrm{R} 29$ & $\mathrm{HO}_{2}+\mathrm{HO}_{2}=\mathrm{H}_{2} \mathrm{O}_{2}+\mathrm{O}_{2}$ \\
\hline $\mathrm{R} 30$ & $\mathrm{H}_{2} \mathrm{O}_{2}+\mathrm{M}=\mathrm{OH}+\mathrm{OH}+\mathrm{M}$ & & \\
\hline
\end{tabular}


At the shown instant of time $0.123 \mathrm{~s}$, the flame is locally quenched around $x \sim 75 \mathrm{~mm}$, where both HRR and OH radicals are absent. This region, referred here also as the flame hole, starts downstream the recirculation zone (cf., Fig. 6 for the recirculation zones of the mean flow), where the scalar dissipation rate is high, and it ends in a downstream location where the scalar dissipation rate is low. In the flame hole, a high concentration of $\mathrm{HO}_{2}$ is present in thick layers where the fuel $\left(\mathrm{CH}_{4}\right)$ is also present. Although not shown in Fig. 10 for brevity, high concentrations of $\mathrm{H}_{2} \mathrm{O}_{2}$ are also found in the flame hole. A certain low level of combustion intermediate, e.g., $\mathrm{H}_{2}$, can also be found in the fuel-rich region of the flame hole where the temperature is lower than the peak flame temperature but higher than the ambient air temperature. When examining the reaction rates in the flame hole, it is found that the reaction rates of $\mathrm{H}_{2}$ and $\mathrm{HRR}$ are negligible, which suggests that the relatively high values of $\mathrm{H}_{2}$ concentration and temperature in the flame hole are due to the transport from the flame region upstream, while not due to local reactions in the flame hole. In the fuel-lean region around the height of the flame hole, $x \sim 75 \mathrm{~mm}$, high concentrations of $\mathrm{HO}_{2}$ and $\mathrm{CH}_{4}$ are shown. The local reaction rates of these species are negligible. Thus, $\mathrm{HO}_{2}$ and $\mathrm{CH}_{4}$ in the fuel-lean region are due to the turbulent transport from the fuel-rich region of the flame hole.

In the upstream fuel-rich region of the flame hole, the reaction rate of $\mathrm{HO}_{2}$ is significantly higher than that in the diffusion flame upstream, i.e., along line-B inside the air tube marked in the $\mathrm{HRR}$ field. The formation of $\mathrm{HO}_{2}$ is through the reaction $\mathrm{H}+\mathrm{O}_{2}+\mathrm{M}=\mathrm{HO}_{2}+\mathrm{M}$ (R9), which is an exothermic reaction giving rise to the HRR shown in the upstream fuel-rich region of the flame hole. In the flame hole the chain terminating reaction R9 is faster than the chain branching reaction $\mathrm{H}+\mathrm{O}_{2}=\mathrm{O}+\mathrm{OH}(\mathrm{R} 1)$, due to the low temperature, which explains the absence of $\mathrm{OH}$ radicals in the flame hole. The $\mathrm{H}$ radicals participating in reaction $\mathrm{R} 9$ comes partly from the fueldissociation reaction $\mathrm{CH}_{4}=\mathrm{CH}_{3}+\mathrm{H}$ (R15). This reaction requires high temperature, and it becomes negligible in the downstream region of the flame hole as the entrainment of the ambient cold air to the flame hole increases along downstream direction. With $\mathrm{H}$ radicals being consumed in $\mathrm{R} 9$, the rate of $\mathrm{HO}_{2}$ formation in the downstream part of the flame hole becomes negligible.

From the above discussion, the onset of a flame hole can be explained as the following. When the high scalar dissipation rate in the flame region (around the iso-line of the stoichiometric mixture fraction) is high, heat loss from the flame to the ambient cold air is high, which leads to a decrease of flame temperature. Subsequently, the radical recombination reaction $\mathrm{R} 9$ is enhanced and the radical branching reaction $\mathrm{R} 1$ is suppressed, as indicated by the absence of $\mathrm{OH}$ radicals and the high $\mathrm{HO}_{2}$ concentration in thick layers. Eventually, when the radicals $\mathrm{H}$, $\mathrm{O}$, and $\mathrm{OH}$ are consumed the reaction rates are negligible and a flame hole is formed. This scenario of flame hole formation is consistent with the rate-ratio asymptotic analyses of non-premixed flames [77,78].

At the downstream boundary of the flame hole, the scalar dissipation rate is low and the HRR becomes significant again, indicating the onset of re-ignition. It is useful to examine the reaction rates in the leading edge of the reaction layers downstream the flame hole, i.e., the region marked as $\mathrm{C}$ in the $\mathrm{OH}$ field, Fig. 10. In region$\mathrm{C}$, an island of high $\mathrm{OH}$ radicals is found around the stoichiometric mixture fraction and $\mathrm{HO}_{2}$ is consumed. In this region, $\mathrm{OH}$ radicals are formed mainly through the reaction $\mathrm{HO}_{2}+\mathrm{H}=\mathrm{OH}+\mathrm{OH}(\mathrm{R} 10)$, which leads to the complete consumption of $\mathrm{HO}_{2}$ in the $\mathrm{OH}$ island. The $\mathrm{H}$ radicals participating in reaction $\mathrm{R} 10$ come mainly from reaction $\mathrm{H}_{2}+\mathrm{OH}=\mathrm{H}_{2} \mathrm{O}+\mathrm{H}(\mathrm{R} 5)$. The fuel dissociation reaction $\mathrm{R} 15$ is relatively unimportant in region-C.

In the flame hole, $\mathrm{H}_{2} \mathrm{O}_{2}$ is formed through the reaction $\mathrm{HO}_{2}+\mathrm{HO}_{2}=\mathrm{H}_{2} \mathrm{O}_{2}+\mathrm{O}_{2}$ (R29). This reaction has zero activation energy [68]. Thus, it is active in the entire flame hole. Owing to this reaction, $\mathrm{H}_{2} \mathrm{O}_{2}$ is found in the broad region in the flame hole, nearly overlapping with the distribution of $\mathrm{HO}_{2}$. The dissociation reaction $\mathrm{H}_{2} \mathrm{O}_{2}+\mathrm{M}=\mathrm{OH}+\mathrm{OH}+\mathrm{M}(\mathrm{R} 30)$ provides the possibility of downstream re-ignition. The reaction rate of R30 
in region-C is however, significantly lower than that of $\mathrm{R} 10$. Thus, it can be concluded that the stabilization of the edge flame downstream the flame hole is not due to the ignition mechanism but rather due to the edge flame propagation.

The HRR distribution suggests a triple flame structure of the edge flame downstream the flame hole, with a leading edge in region-C, followed by a fuel-rich reaction front around the centerline of the jet where $\mathrm{HO}_{2}$ is oxidized through reaction R10, along with fuel oxidation reactions forming combustion intermediates, e.g., $\mathrm{H}_{2}$. This gives rise to the inner HRR branch. A high HRR branch is shown around the stoichiometric mixture fraction where $\mathrm{H}_{2}$ is oxidized. This HRR layer corresponds to the diffusion flame branch of the triple flame. Outside the diffusion flame branch, a lean premixed flame branch is seen, in which $\mathrm{HO}_{2}$ and the fuel leaked through the flame hole are oxidized, cf., line-A marked in the HRR field. Since the mixture upstream of the leading front of the triple flame contains not only fuel and oxygen but also reactant intermediates such as $\mathrm{H}_{2}$, $\mathrm{HO}_{2}, \mathrm{H}_{2} \mathrm{O}_{2}$, and $\mathrm{CH}_{2} \mathrm{O}$ (not shown for brevity), the leading front is an ignition assisted partially premixed flame.

\subsection{Local flame extinction and re-ignition in flame Fno55}

The flame structure inside the airflow tube and in the proximity of the fuel jet in flame Fno55 is similar to that in the flame Fno33, cf., Figs. 10 and 11. The swirl induced recirculation flow enables the mixing of fuel and air inside the air tube and the stabilization of a diffusion flame. The HRR distribution exhibits a two-layer flame structure, one along $Z_{s t}$, that is attributed to the reactions with $\mathrm{OH}$ radicals through $\mathrm{R} 5$ and $\mathrm{R} 7$ (cf. Table 2), and one on the fuel-lean side that is attributed to the forming of $\mathrm{HO}_{2}$ through $\mathrm{R} 9$.
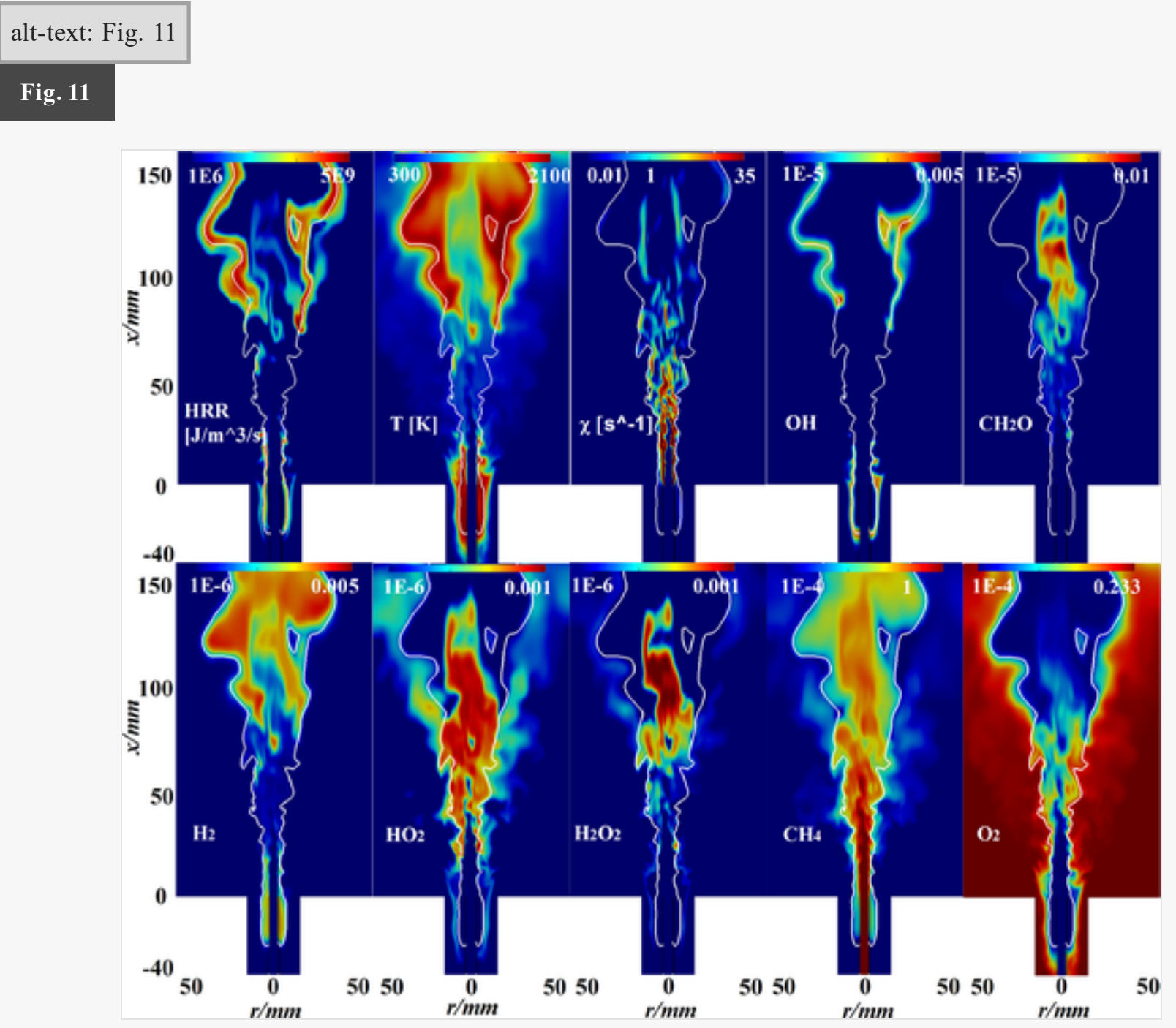
Instantaneous distribution of HRR, temperature, scalar dissipation rate, and mass fractions of $\mathrm{OH}, \mathrm{CH}_{2} \mathrm{O}, \mathrm{H}_{2}, \mathrm{HO}_{2}, \mathrm{H}_{2} \mathrm{O}_{2}$, $\mathrm{CH}_{4}$, and $\mathrm{O}_{2}$ for flame Fno55, in which $\chi$ and mass fractions of $\mathrm{HO}_{2}, \mathrm{H}_{2} \mathrm{O}_{2}$, and $\mathrm{CH}_{4}$ are in $\log$-scale.

Compared with the structure of flame Fno33, the local extinction region in flame Fno55 is significantly larger. The higher fuel jet velocity in flame Fno55 gives rise to a lower effective swirl number and therefore a weaker vortex breakdown and a smaller internal recirculation zone, thus resulting in a higher gradient of mixture fraction, and a higher scalar dissipation rate in flame Fno55, with the iso-line of the stoichiometric mixture fraction closer to the high scalar dissipation rate region. This results in an earlier local extinction of the flame, as seen in the $\mathrm{OH}$ field shown in Fig. 11. The mechanism of local extinction is the same as that in flame Fno33. The high scalar dissipation rate gives rise to a faster mixing of air into the flame and this resulting in faster cooling of the flame temperature than heat release from the chemical reactions in the flame. Subsequently, the chain terminating reaction R9 overtakes the chain branching reaction R1, leading to flame quenching. This quenching mechanism explains the high concentration of $\mathrm{HO}_{2}$ in the flame hole. Due to the lack of radicals in the flame hole, the consumption of $\mathrm{HO}_{2}$ is mainly through reaction $\mathrm{R} 29$, which gives rise to the formation of $\mathrm{H}_{2} \mathrm{O}_{2}$ in the downstream region of the flame hole.

The scalar dissipation rate decreases in the flame hole along the downstream direction, and eventually the mixture is re-ignited. After reaching a statistically stationary state, the leading flame front downstream of the flame hole shows a triple flame structure, similar to that of flame Fno33. The HRR field shows a high heat release rate around the iso-surface of $Z_{s t}$, and a relatively low HRR on the fuel-rich side and the fuel-lean side of the mixture, cf. the right branches of the HRR field shown in Fig. 11. These HRR layers correspond respectively to the diffusion flame branch and the fuel-rich premixed flame branch of the triple flame. Across the fuel-rich premixed flame, the fuel is partially oxidized and oxygen is consumed, along with a nearly complete oxidation of $\mathrm{H}_{2} \mathrm{O}_{2}, \mathrm{HO}_{2}$ and $\mathrm{CH}_{2} \mathrm{O}$. Since combustion intermediates, e.g., $\mathrm{H}_{2} \mathrm{O}_{2}$ and $\mathrm{HO}_{2}$, exist in the mixture upstream the triple flame, the structure of the triple flame is different from the conventional triple flame that has only fuel and air in the upstream mixture.

A temporal evolution of the iso-surface of the stoichiometric mixture fraction is displayed in Fig. 12, which shows the 3D topology of the diffusion flame branch and the leading edge of the triple flame structure (note that the fuel-rich premixed flame branch is in the inner region enveloped by the $3 \mathrm{D}$ iso-surface of $Z_{s t}$ shown in the figure). The temperature in the diffusion flame branch is rather uniform showing stable combustion without local extinction. The shape of the flame surface varies in time due to both the large scale flow motion (i.e., swirling flow motion) that is responsible for the counter-clockwise rotation (from top-view) of the 3D structure, and the small-scale turbulence/flame interactions that are responsible for the surface wrinkling. The flame leading front is stabilized in the flame height region $x \sim 80-110 \mathrm{~mm}$. Moreover, as discussed earlier, the leading front of the triple flame is an ignition assisted flame propagation. 


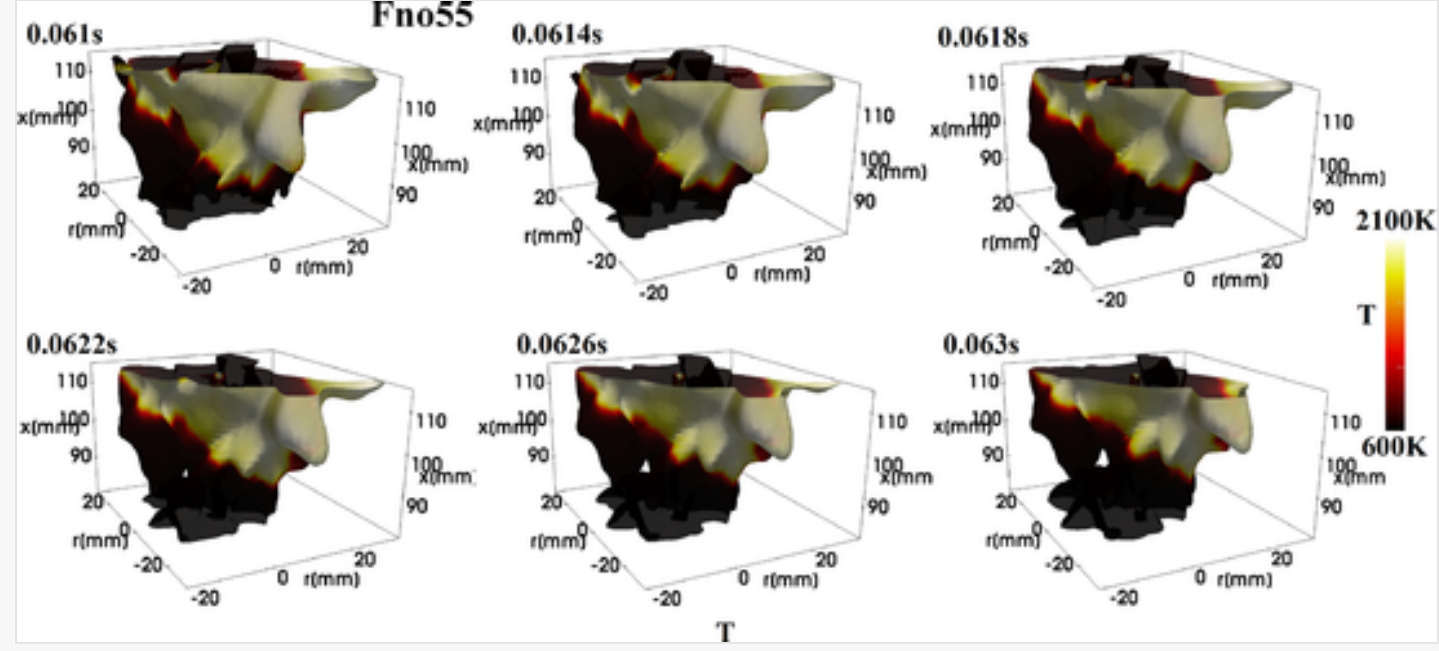

Instantaneous $T$ contours on the 3D iso-surface of $Z_{s t}$ for flame Fno55 during the time interval $0.061 s<t<0.063 s . t=0$ denotes an arbitrary time when the flame is at the statistically stationary state.

To evaluate the effect of diffusion and chemical reaction at the leading flame front the budget terms of the transport equation for the mass fraction of $\mathrm{CO}_{2}$ are compared in Fig. 13. The budget terms are calculated in a small domain, around the flame height of $x=90 \mathrm{~mm}$, with a $2 \mathrm{~mm}$ interval in the axial direction, around the flame part of the iso-surface of mixture fraction $(0.05<Z<0.06$ and $T>1500)$. Figure 13 displays the maximal values of the diffusion term and the reaction rate of $\mathrm{CO}_{2}$ in the small leading flame front domain. Also shown in the figure is the ratio of the reaction rate term to the diffusion term, which is referred here as the Damköhler number, $D a$. It is shown that $D a$ is approximately $2 t_{-}$, indicating that the reaction rate is $2 t_{-}=7$ folds of the diffusion term. This value is higher than that in a typical triple flame [79], which illustrates the significant contribution of the combustion intermediates, e.g., $\mathrm{HO}_{2}$, in the flame hole upstream of the triple flame, to the chemical reactions at the leading flame front. Although smaller than the reaction rate, the diffusion term is still significantly larger than that of an ignition front that has a value of $D a$ of 10 or higher $[80,81]$.

alt-text: Fig. 13

Fig. 13
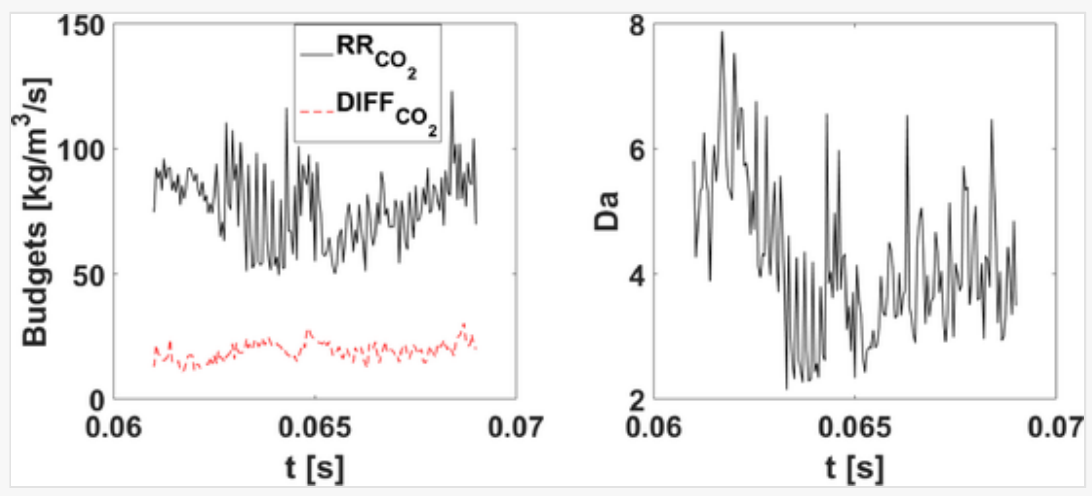
(a) Budget analyses of $\mathrm{CO}_{2}$ and (b) $D a$ number around the flame front $(T>1500 \mathrm{~K}, 2 \mathrm{~mm}$ interval in axial direction) along a flow-through time.

\section{Conclusions}

Local extinction and re-ignition of non-premixed swirling methane/air flames in a laboratory burner are investigated using LES with a transported PDF sub-grid scale model within the Eulerian Stochastic Field framework. Three flames cover a conventional diffusion flame with a low fuel jet velocity, and two flames with local extinction and re-ignition under high fuel jet velocity conditions. The Smooke chemical kinetic mechanism is employed, in which key elementary reactions are identified to explain the extinction and re-ignition process. Several mechanisms of local extinction and re-ignition are evaluated. The following conclusions are drawn:

- The fuel jet velocity exhibits a significant impact on the flame structures in the present nonpremixed swirling methane/air flames. As the fuel velocity increases, the effective swirl number decreases, and the size of the recirculation zone induced by vortex breakdown decreases in both the axial and the radial directions. The stoichiometric mixture in the downstream region of the recirculation zone is near the central fuel jet flow stream where the scalar dissipation rate is high. The flame in the upstream portion of the recirculation zone is maintained, while at the downstream location of the recirculation zone the flame is quenched due to the high scalar dissipation rate. A lifted flame is stabilized at a further downstream location where the scalar dissipation rate is low.

- The local flame extinction process in the proximity of the burner exit is dynamic, and the scalar dissipation rate $\chi$ under which a flame region is locally quenched is lower than the referenced scalar dissipation rate for flame extinction of a 1D steady laminar flame, $\chi_{q}$. A flame hole formed earlier can be re-ignited when the $\chi$ drops to significantly below the $\chi_{q}$. The re-ignition of the flame hole is governed by the mechanism of turbulent flame folding. Hot gas from the surrounding diffusion flame is transported to the flame hole by turbulent eddies and molecular diffusion, which in turn triggers the chemical reactions leading gradually to the shrinking/disappearing of the flame hole.

- The mechanism of local extinction in the flame hole and at the trailing edge of the diffusion flame in the downstream part of the recirculation zone is similar to the mechanism of quenching of a steady laminar flame. When the scalar dissipation rate is high, air diffusion to the reaction zone of the flame is enhanced, and leakage of air through the reaction zone to the fuel-rich side of the mixture is increased, thus leading to a decrease of the flame temperature and slowing down the heat release rate.

- The leading fronts of the lifted flames downstream the local extinction region in the high fuel jet velocity flames exhibit a triple flame structure. These triple flames are different from a conventional lifted jet flame. Due to the existence of the diffusion flames in the upstream recirculation zone in the proximity of the burner exit, the mixture in the flame hole is a mixture of fuel, air, and combustion intermediates including $\mathrm{HO}_{2}, \mathrm{H}_{2} \mathrm{O}_{2}$, and $\mathrm{CH}_{2} \mathrm{O}$, etc. These species contribute to the radical formation and heat release in the triple flame. As a result, the stabilization of the downstream flame is by the mechanism of ignition assisted partially premixed flame propagation. 
It is shown that LES with PDF-ESF sub-grid model can simulate the local extinction and re-ignition process reasonably well. In particular, the method allows for the elementary reactions to be directly coupled with the subgrid turbulence and the local thermodynamic variables. In this regard, it is expected that the prediction is affected by the chemical kinetic mechanism employed. When a more detailed mechanism is used a more accurate prediction of the local extinction and re-ignition process is expected.

\section{Declaration of Competing Interest}

The authors declare that they have no known competing financial interests or personal relationships that could have appeared to influence the work reported in this paper.

\section{Acknowledgments}

The experimental work was supported by competitive research funding from King Abdullah University of Science and Technology (KAUST), Saudi Arabia. The LES work was partly sponsored by Swedish Research Council (VR), and the Swedish Energy Agency (STEM) through the national center for combustion science and technologies (CeCOST) and Lund University Competence Center for Combustion Process (KC-FP). S. Yu and X. Liu were sponsored by China Scholarship Council (CSC). The computations were performed using the computer facilities provided by High Performance Computing Center North (HPC2N), and Center for Parallel Computers (PDC).

\section{Appendix A}

When the ESF-PDF method is used, the number of stochastic fields is a model parameter to be selected. Since the ESF-PDF method is computationally demanding, it is desirable to choose a minimal number of fields for an acceptable numerical accuracy. A sensitivity study is carried out to investigate the convergence behaviour of the ESF-PDF results with respect to the variation of the number of stochastic fields. The study was carried out for the flame Fno33.

Figure 14 displays the convergence behaviour of two key terms in the PDF equation, the Wiener and the reaction rate term for the mass fraction of $\mathrm{OH}$ radicals (cf. Eq. (7)), along the flame height. The data are extracted from one iso-line of stoichiometric mixture fraction $Z_{s t}$ (the white line in Fig. 14(c)). The ensemble average of the Wiener term using the different fields should converge to zero as the number of stochastic fields increases, while the ensemble average of reaction rate should converge to a non-zero value. It can be seen that ensemble averaged reaction rate of $\mathrm{OH}$ mass fraction converges reasonably well with 8 stochastic fields. The ensemble average coincides well with that from 12, 16, and 32 stochastic fields. The convergence of the ensemble averaged Wiener term requires however a larger number of stochastic fields, with 32 fields still yielding certain departure from the ideally converged value of zero. The use of 8 fields yields an ensemble averaged value about $25 \%$ of that from 2 fields. However, the Wiener term is in general smaller than that of the reaction rate term, with the latter having a more dominant influence on the results as shown below.

alt-text: Fig. 14

Fig. 14 


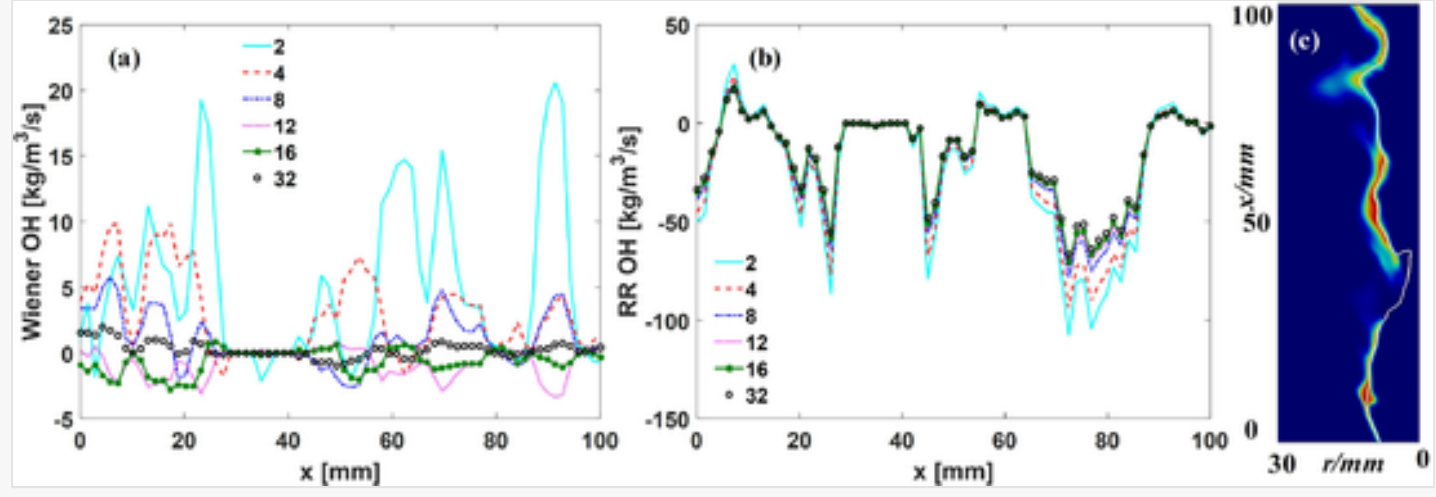

The ensemble average of Wiener term (a) and reaction rate term (b) in the PDF equation for OH mass fraction (Eq. (7)) extracted along a white line shown in (c) computed using 2, 4, 8, 12, 16, and 32 fields.

Figure 15 shows the time averaged mean mass fraction of $\mathrm{OH}$ radicals conditioned on the stoichiometric mixture fraction $\left(Y_{\mathrm{OH} \mid Z_{s t}}\right)$ from ESF-PDF simulations using 2, 4, 8, 12, and 16 stochastic fields. The time average is based on data collected during 5ms, which covers about 10 local extinction and re-ignition events, cf. Fig. 9. It is shown that as the number of the stochastic fields increases, the $Y_{O H \mid} \mid Z_{s t}$ profiles converge to a single profile. The profiles from 12 and 16 stochastic fields overlap very well, while the profile from 8 fields are reasonably well converged to the profiles of the 12 and 16 fields. Similar comparison has been made for the time averaged temperature profile conditioned on the stoichiometric mixture fraction. It is found that the time averaged temperature profile from 8 fields is in a closer agreement with that from the 12 and 16 fields than for the $Y_{O H \mid Z_{s t}}$ profiles (for brevity the temperatures are not shown).

alt-text: Fig. 15

\section{Fig. 15}

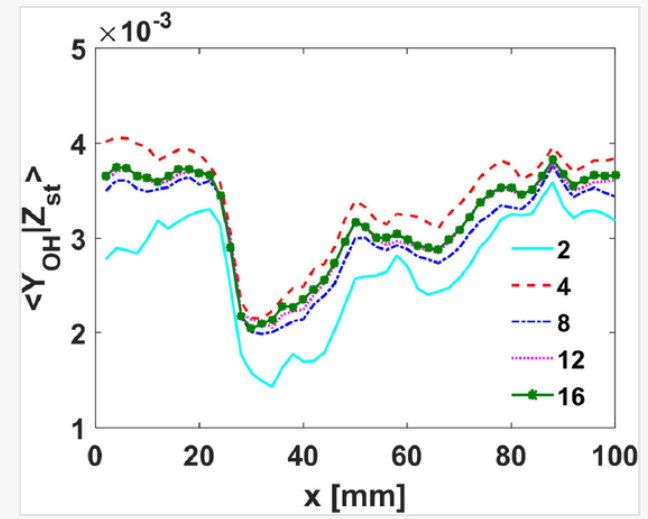

Time averaged mean mass fraction of $\mathrm{OH}$ radicals conditioned on stoichiometric mixture fraction based on $2,4,8,12$, and 16 stochastic fields.

\section{References}


[1] Peters N., Laminar flamelet concepts in turbulent combustion, Symp. (Int.) Combust. 21 (1) (1986) 1231-1250.

[2] Masri A., Dibble R., Barlow R., The structure of turbulent nonpremixed flames revealed by Raman-Rayleigh-LIF measurements, Progr. Energy Combust. Sci. 22 (4) (1996) 307-362.

[3] Kaiser S., Frank J., Spatial scales of extinction and dissipation in the near field of non-premixed turbulent jet flames, Proc. Combust. Inst. 32 (2) (2009) 1639-1646.

[4] Sutton J.A., Driscoll J.F., Imaging of local flame extinction due to the interaction of scalar dissipation layers and the stoichiometric contour in turbulent non-premixed flames, Proc. Combust. Inst. 31 (1) (2007) 1487-1495.

[5] Masri A., Kalt P., Al-Abdeli Y., Barlow R., Turbulence-chemistry interactions in non-premixed swirling flames, Combust. Theory Modell. 11 (5) (2007) 653-673.

[6] Saitoh T., Otsuka Y., Unsteady behavior of diffusion flames and premixed flames for counter flow geometry, Combust. Sci. Technol. 12 (4-6) (1976) 135-146.

[7] Haworth D., Drake M., Pope S., Blint R., The importance of time-dependent flame structures in stretched laminar flamelet models for turbulent jet diffusion flames, Sympos. (Int.) Combust., 22, Elsevier, 1989, pp. 589-597.

[8] Pitsch H., Fedotov S., Investigation of scalar dissipation rate fluctuations in non-premixed turbulent combustion using a stochastic approach, Combust. Theory Model. 5 (1) (2001) 41-57.

[9] Watson K.A., Lyons K.M., Donbar J.M., Carter C.D., Scalar and velocity field measurements in a lifted CH4ü air diffusion flame, Combust. Flame 117 (1) (1999) 257-271.

[10] Watson K.A., Lyons K.M., Carter C.D., Donbar J.M., Simultaneous two-shot CH planar laserinduced fluorescence and particle image velocimetry measurements in lifted $\mathrm{CH} 4$ /air diffusion flames, Proc. Combust. Inst. 29 (2) (2002) 1905-1912.

[11] Lyons K.M., Watson K.A., Carter C.D., Donbar J.M., On flame holes and local extinction in lifted-jet diffusion flames, Combustion and Flame 142 (3) (2005) 308-313.

[12] Masri A.R., Kalt P.A., Barlow R.S., The compositional structure of swirl-stabilised turbulent nonpremixed flames, Combust. Flame 137 (1-2) (2004) 1-37.

[13] Pantano C., Direct simulation of non-premixed flame extinction in a methaneü air jet with reduced chemistry, J. Fluid Mech. 514 (2004) 231-270.

[14] Hawkes E.R., Sankaran R., Chen J.H., Extinction and reignition in direct numerical simulations of $\mathrm{CO} / \mathrm{H} 2$ temporal plane jet flames, Report, Oak Ridge National Lab.(ORNL), Oak Ridge, TN (United States); Center for Computational Sciences, 2007.

[15] Hawkes E.R., Sankaran R., Sutherland J.C., Chen J.H., Scalar mixing in direct numerical simulations of temporally evolving plane jet flames with skeletal $\mathrm{CO} / \mathrm{H} 2$ kinetics, Proc. Combust. 
Inst. 31 (1) (2007) 1633-1640.

[16] Garmory A., Mastorakos E., Capturing localised extinction in Sandia Flame F with LESü CMC, Proc. Combust. Inst. 33 (1) (2011) 1673-1680.

[17] Garmory A., Mastorakos E., Sensitivity analysis of LESü CMC predictions of piloted jet flames, Int. J. Heat Fluid Flow 39 (2013) 53-63.

[18] Sripakagorn P., Mitarai S., Kosály G., Pitsch H., Extinction and reignition in a diffusion flame: a direct numerical simulation study, J. Fluid Mech. 518 (2004) 231-259.

[19] Steinberg A.M., Boxx I., Arndt C.M., Frank J.H., Meier W., Experimental study of flame-hole reignition mechanisms in a turbulent non-premixed jet flame using sustained multi-khz PIV and crossed-plane OH PLIF, Proc. Combust. Inst. 33 (1) (2011) 1663-1672.

[20] Frouzakis C.E., Tomboulides A.G., Lee J., Boulouchos K., From diffusion to premixed flames in an H2/air opposed-jet burner: the role of edge flames, Combust. Flame 130 (3) (2002) 171-184.

[21] Gong C., Jangi M., Bai X.-S., Diesel flame lift-off stabilization in the presence of laser-ignition: a numerical study, Combust. Theory Model. 19 (6) (2015) 696-713.

[22] Vervisch L., Poinsot T., Direct numerical simulation of non-premixed turbulent flames, Annu. Rev. Fluid Mech. 30 (1) (1998) 655-691.

[23] Buckmaster J., Weber R., Edge-flame-holding, Symp. (Int.) Combust. 26 (1996) 1143-1149.

[24] Favier V., Vervisch L., Investigating the effects of edge flames in liftoff in non-premixed turbulent combustion, Symp. (Int.) Combust. 27 (1998) 1239-1245.

[25] Juddoo M., Masri A., High-speed OH-PLIF imaging of extinction and re-ignition in non-premixed flames with various levels of oxygenation, Combust. Flame 158 (5) (2011) 902-914.

[26] Elbaz A.M., Roberts W.L., Experimental study of the inverse diffusion flame using high repetition rate oh/acetone PLIF and PIV, Fuel 165 (2016) 447-461.

[27] Wohl K., Kapp N.M., Gazley C., The stability of open flames, Symp. Combust. Flame Explos. Phenom. 3 (1) (1948) 3-21.

[28] Vanquickenborne L., Van Tiggelen A., The stabilization mechanism of lifted diffusion flames, Combust. Flame 10 (1) (1966) 59-69.

[29] Müller C.M., Breitbach H., Peters N., Partially premixed turbulent flame propagation in jet flames, Symp. (Int.) Combust. 25 (1) (1994) 1099-1106.

[30] Peters N., Turbulent Combustion, Cambridge university press, 2000.

[31] Lyons K.M., Toward an understanding of the stabilization mechanisms of lifted turbulent jet flames: experiments, Progr. Energy Combust. Sci. 33 (2) (2007) 211-231.

[32] Buckmaster J., Edge-flames, Progr. Energy Combust. Sci. 28 (5) (2002) 435-475. 
Kempf A., Malalasekera W., Ranga-Dinesh K.K.J., Stein O., Large eddy simulations of swirling non-premixed flames with flamelet models: a comparison of numerical methods, Flow Turbul. Combust. 81 (4) (2008) 523-561.

[34] Ihme M., Pitsch H., Prediction of extinction and reignition in nonpremixed turbulent flames using a flamelet/progress variable model: 2. Application in LES of Sandia flames D and E, Combust. Flame 155 (1-2) (2008) 90-107.

[35] Klimenko A.Y., Bilger R.W., Conditional moment closure for turbulent combustion, Progr. Energy Combust. Sci. 25 (6) (1999) 595-687.

[36] Navarro-Martinez S., Kronenburg A., Di Mare F., Conditional moment closure for large eddy simulations, Flow Turbul. Combust. 75 (1-4) (2005) 245-274.

[37] Karpetis A.N., Barlow R.S., Measurements of flame orientation and scalar dissipation in turbulent partially premixed methane flames, Proc. Combust. Inst. 30 (1) (2005) 665-672.

[38] Kronenburg A., Kostka M., Modeling extinction and reignition in turbulent flames, Combust. Flame 143 (4) (2005) 342-356.

[39] Kronenburg A., Papoutsakis A., Conditional moment closure modeling of extinction and reignition in turbulent non-premixed flames, Proc. Combust. Inst. 30 (1) (2005) 759-766.

[40] Zhang H., Garmory A., Cavaliere D.E., Mastorakos E., large eddy simulation/conditional moment closure modeling of swirl-stabilized non-premixed flames with local extinction, Proc. Combust. Inst. 35 (2) (2015) 1167-1174.

[41] Ihme M., Pitsch H., Prediction of extinction and reignition in nonpremixed turbulent flames using a flamelet/progress variable model: 1 . A priori study and presumed pdf closure, Combust. Flame 155 (1-2) (2008) 70-89.

[42] Lignell D.O., Chen J.H., Schmutz H.A., Effects of damkhler number on flame extinction and reignition in turbulent non-premixed flames using DNS, Combust. Flame 158 (5) (2011) 949-963.

[43] Masri A., Pope S., PDF calculations of piloted turbulent nonpremixed flames of methane, Combust. Flame 81 (1) (1990) 13-29.

[44] Tang Q., Xu J., Pope S.B., Probability density function calculations of local extinction and NO production in piloted-jet turbulent methane/air flames, Proc. Combust. Inst. 28 (1) (2000) 133-139.

[45] Masri A., Pope S., Dally B., Probability density function computations of a strongly swirling nonpremixed flame stabilized on a new burner, Proc. Combust. Inst. 28 (1) (2000) 123-131.

[46] James S., Zhu J., Anand M., Large eddy simulations of turbulent flames using the filtered density function model, Proc. Combust. Inst. 31 (2) (2007) 1737-1745.

[47] Jones W., Prasad V., Large eddy simulation of the Sandia Flame Series (Dü F) using the Eulerian stochastic field method, Combust. Flame 157 (9) (2010) 1621-1636.

[48] Prasad V.N., Juddoo M., Masri A.R., Jones W.P., Luo K.H., Investigation of extinction and reignition in piloted turbulent non-premixed methaneü air flames using LES and high-speed OH- 
LIF, Combust. Theory Model. 17 (3) (2013) 483-503.

[49] Jones W., Navarro-Martinez S., Large eddy simulation of autoignition with a subgrid probability density function method, Combust. Flame 150 (3) (2007) 170-187.

[50] Jones W.P., Marquis A.J., Prasad V.N., LES of a turbulent premixed swirl burner using the Eulerian stochastic field method, Combust. Flame 159 (10) (2012) 3079-3095.

[51] Fredrich D., Jones W., Marquis A.J., The stochastic fields method applied to a partially premixed swirl flame with wall heat transfer, Combust. Flame 205 (2019) 446-456.

[52] Brauner T., Jones W., Marquis A., Les of the cambridge stratified swirl burner using a sub-grid pdf approach, Flow Turbul. Combust. 96 (4) (2016) 965-985.

[53] Dodoulas I.A., Navarro-Martinez S., Analysis of extinction in a non-premixed turbulent flame using large eddy simulation and the chemical explosion mode analysis, Combust. Theory Model. 19 (1) (2015) 107-129.

[54] Elbaz A.M., Roberts W.L., Investigation of the effects of quarl and initial conditions on swirling non-premixed methane flames: flow field, temperature, and species distributions, Fuel 169 (2016) $120-134$.

[55] Liu X., Elbaz A., Gong C., Bai X., Zheng H., Roberts W., Effect of burner geometry on swirl stabilized methane/air flames: a joint LES/OH-PLIF/PIV study, Fuel 207 (2017) 533-546.

[56] Elbaz A.M., Yu S., Liu X., Bai X.S., Khesho I., Roberts W.L., An experimental/numerical investigation of the role of the quarl in enhancing the blowout limits of swirl-stabilized turbulent non-premixed flames, Fuel 236 (2019) 1226-1242.

[57] Smagorinsky J., General circulation experiments with the primitive equations: I. The basic equations, Mon. Weather Rev. 91 (1963) 99-164.

[58] Mustata R., Valiño L., Jiménez C., Jones W., Bondi S., A probability density function Eulerian Monte Carlo field method for large eddy simulations: application to a turbulent piloted methane/air diffusion flame (Sandia D), Combust. Flame 145 (1-2) (2006) 88-104.

[59] Triantafyllidis A., Mastorakos E., Eggels R.L.G.M., Large eddy simulations of forced ignition of a non-premixed bluff-body methane flame with conditional moment closure, Combust. Flame 156 (12) (2009) 2328-2345.

[60] Hodzic E., Jangi M., Szasz R.-Z., Bai X.-S., Large eddy simulation of bluff body flames close to blow-off using an eulerian stochastic field method, Combust. Flame 181 (2017) 1-15.

[61] Dopazo C., O’Brien E.E., Functional formulation of nonisothermal turbulent reactive flows, Phys. Fluids 17 (11) (1974) 1968-1975.

[62] Fox R., Villermaux J., Unsteady-state iem model: numerical simulation and multiple-scale perturbation analysis near perfect-micromixing limit, Chem. Eng. Sci. 45 (2) (1990) 373-386.

[63] Mitarai S., Riley J., Kosály G., Testing of mixing models for monte carlo probability density function simulations, Phys. Fluids 17 (4) (2005) 47101. 
[64] Valiño L., A field Monte Carlo formulation for calculating the probability density function of a single scalar in a turbulent flow, Flow Turbul. Combust. 60 (2) (1998) 157-172.

[65] Jones W.P., Prasad V.N., Large Eddy Simulation of the Sandia Flame Series (D-F) using the Eulerian stochastic field method, Combust. Flame 157 (9) (2010) 1621-1636.

[66] OpenFoam, Openfoam foundationweb site: http://openfoam.org, 2017,.

[67] E. Hodzic S. Yu A.A. Subash X. Liu X. Liu R.-Z. Szasz X.-S. Bai Z. Li M. Alden Numerical and experimental investigation of the CeCOST swirl burner ASME Turbo Expo 2018: Turbomachinery Technical Conference and Exposition 2018 American Society of Mechanical Engineers V04AT04A056-V04AT04A056

[68] Smooke M., Giovangigli V., Reduced Kinetic Mechanisms and Asymptotic Approximation for Methane-Air Flames, Springer-Verlag, Berlin, 1991.

[69] G.P. Smith, et, al., GRI 3.0 mechanismweb site: http://www.me.berkeley.edu/gri-mech/, 2017, .

[70] Feikema D., Chen R.-H., Driscoll J.F., Enhancement of flame blowout limits by the use of swirl, Combust. Flame 80 (2) (1990) 183-195.

[71] Syred N., A review of oscillation mechanisms and the role of the precessing vortex core (PVC) in swirl combustion systems, Progr. Energy Combust. Sci. 32 (2006) 93-161.

[72] Hewson J., Kerstein A., Local extinction and reignition in nonpremixed turbulent CO/H 2/N 2 jet flames, Combustion Sci. Technol. 174 (5-6) (2002) 35-66.

[73] Pitsch H., Steiner H., Scalar mixing and dissipation rate in large-eddy simulations of non-premixed turbulent combustion, Proc. Combust. Inst. 28 (1) (2000) 41-49.

[74] Girimaji S.S., Zhou Y., Analysis and modeling of subgrid scalar mixing using numerical data, Phys. Fluids 8 (5) (1996) 1224-1236.

[75] Kistler J., Sung C., Kreut T., Law C.K., Nishioka M., Extinction of counterflow diffusion flames under velocity oscillations, Symp. (Int.) Combust. 26 (1) (1996) 113-120.

[76] Mauß F., Keller D., Peters N., A lagrangian simulation of flamelet extinction and re-ignition in turbulent jet diffusion flames, Symp. (Int.) Combust. 23 (1) (1991) 693-698.

[77] Seshadri K., Peters N., Asymptotic structure and extinction of methane/air diffusion flames, Combust. Flame 73 (1) (1988) 23-44.

[78] Bai X.-S., Seshadri K., Rate-ratio asymptotic analysis of non-premixed methane flames, Combust. Theory Model. 3 (1) (1999) 51-75.

[79] Karami S., Hawkes E.R., Talei M., Chen J.H., Mechanisms of flame stabilisation at low lifted height in a turbulent lifted slot-jet flame, J. Fluid Mech. 777 (2015) 633-689.

[80] Chen J.H., Hawkes E.R., Sankaran R., Mason S.D., Im H.G., Direct numerical simulation of

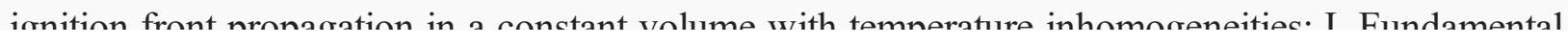


Query: Please confirm that givennames and surnames have been identified correctly.

Answer: 